\title{
DAS GENERALKOMMISSARIAT DES HEILIGEN LANDES IN WIEN - EINE WIEDERENTDECKUNG DES 19. JAHRHUNDERTS
}

Gerald Stourzh zum 75. Geburtstag

Wenn in den letzten Jahren allmählich eine Neubewertung des Stellenwerts von Religion für das 19. Jahrhundert einsetzt, an deren Anfang "die Entdekkung einer verblüffenden Diskrepanz: zwischen der historiographischen Geringschätzung von Religion und ihrer prägenden Rolle in Politik und Wirtschaft, in Gesellschaft und Kultur« steht, und das vertraute Bild, wonach sich Religion »wie ein eiszeitlicher Gletscher in das 19. Jahrhundert hineingeschoben [habe], wo er unter der strahlenden Sonne am bürgerlichen Wertehimmel langsam aber stetig abschmilzt«, dadurch eine Akzentverschiebung erlebt ${ }^{1}$, so soll im folgenden eine in Wien angesiedelte und große Breitenwirkung erzielende kirchliche Einrichtung vorgestellt werden: das für die katholische Mission in Palästina tätige »Generalkommissariat des Heiligen Landes«, auf das das in den Quellen als »katholisches Österreich « bezeichnete Gesellschaftssegment im Verband von Kirche, hoher Politik und geistesgeschichtlichen Strömungen um die Mitte des 19. Jahrhunderts bewußt zurückgriff.

Das im Wiener Franziskanerkloster beheimatete Generalkommissariat des Heiligen Landes ist mit seinem Gründungsjahr 1633 ein Kind der Gegenreformation. Bei der Wiedererrichtung 1843 sollte es bereits auf eine über 200jährige wechselvolle Geschichte zurückblicken können und in den folgenden Jahrzehnten »seine höchste Blüte ${ }^{2}$ erreichen.

$1 \mathrm{Vgl}$. die anregenden Ausführungen von Olaf BLASCHKE, Das 19. Jahrhundert: Ein Zweites Konfessionelles Zeitalter?, in: Geschichte und Gesellschaft 26 (2000) S. 38-75, hier S. 38, 44. Für die Habsburgermonarchie zumindest gilt es noch immer mit Peter Leisching eine mangelnde Beachtung der gesellschaftlichen Bezüge von Religion zu konstatieren: »Noch fehlen die Arbeiten über den historischen Kontext der gesellschaftlichen Formation und ihrer Voraussetzungen, um zu ermessen, in welchem Ausmaß dem österreichischen Katholizisimus als soziales Phänomen ein gesellschaftlicher Stellenwert zuerkannt werden kann.« Peter LEISCHING, Die römisch-katholische Kirche in Cisleithanien, in: Adam WaNDRUSZKa, Peter URBanITSCH (Hg.), Die Habsburgermonarchie 1848-1918, Bd. 4: Die Konfessionen, Wien ${ }^{2} 1995$, S. 2.

2 Bedeutung der Kommissariate des Heiligen Landes, in: Österreichische Pilgerbriefe 1 (1932) S. 2f., hier S. 3. 


\section{Die Vorgeschichte}

Um die Mittel aufzubringen, die die Erhaltung des Heiligen Landes, der dortigen Schulen und Missionen verlangte, errichtete der Franziskanerorden frühzeitig in verschiedenen Ländern Sammelstellen, die den Kontakt mit der Kustodie $^{3}$ hielten; diese Kommissariate erhielten von den Generaloberen des Ordens spezielle Vollmachten und wurden durch päpstliche Konstitutionen bestätigt. Das Kapitel im Jahr 1621 hatte in jeder Nation einen »Commissarius « oder "Procurator generalis« für das Heilige Land aufgestellt, dem in jeder Provinz »Vice-Commissarii« beigegeben waren ${ }^{4}$.

Die Chronik der österreichischen Franziskanerprovinz nennt als Gründer des Wiener Generalkommissariats Ordensgeneral P. Johannes B. de Campagne, der 1633 mit Zustimmung von Kaiser Ferdinand II. P. Petrus de Orosco aus der spanischen Ordensprovinz als ersten Generalkommissar einsetzte. Das Wirkungsgebiet des Wiener Kommissariats umfaßte das ganze Römische Reich Deutscher Nation und sollte wie die drei Kommissariate in Rom, Paris und Madrid „Generalkommissariat des Heiligen Landes« heißen. Daß ein Spanier zum Wiener Generalkommissar ernannt wurde, erklärt sich aus der damaligen, nach Spanien gerichteten Ordenspolitik ${ }^{5}$.

Während zunächst häufig Ausländer als Generalkommissare in Wien fungierten, verordnete Kaiser Leopold I. am 11. Februar 1664 und noch einmal am 24. Februar 1693, daß in Zukunft nur Einheimische mit diesem Amt betraut werden sollten und sich diese überdies mit kaiserlichen Patenten zur Vornahme der jährlichen Kollekten zu versehen hätten. Diese Maßnahme wurde unter Kaiser Joseph I. am 24. Februar 1706 erneuert und von Kaiser Karl VI. am 5. Januar 1714 erneut mit dem Zusatz eingeschärft, daB die Sammlungen in Zukunft durch die Regierungsorgane bestens unterstützt werden sollten ${ }^{6}$.

3 Bereits 1219 war der Ordensgründer Franz von Assisi mit einigen Brüdern im Heiligen Land; 1342 vertraute Papst Clemens VI. mit der Bulle vom 21. November den Franziskanern die Obsorge über die Heiligen Stätten an. Das General-Commissariat des heiligen Landes in Wien, in: Denkblatt des österreichisch-ungarischen Pilgerhauses »zur heiligen Familie« in Jerusalem, hg. vom Curatorium des Pilgerhauses, Wien 1896, S. 5-7, hier S. 5. Die Kustodie beschränkte sich nicht auf Palästina, sondern erstreckte sich auch auf Syrien, Unterägypten und Zypern.

4 Vgl. Heribert HOLZAPFEL, Handbuch der Geschichte des Franziskanerordens, Freiburg im Breisgau 1909, S. 552; und Matthias EISTERER, Erste allgemeine österreichische Pilgerfahrt ins Heilige Land zur Feier des diamantenen Priester-Jubiläums Sr. Heiligkeit Papst Leo XIII. und des goldenen Regierungs-Jubiläums Sr. Apost. Majestät Kaiser Franz Josef I. 12. April bis 16. Mai 1898, Wien 1898, S. 144.

5 Vgl. P. Rigobert WASNER, Geschichte des General-Kommissariates von Wien, in: 300 Jahre General-Kommissariat des Heiligen Landes in Wien (Jubiläumsnummer der Österreichischen Pilgerbriefe April-Juni 1933) S. 4-24, hier S. 7.

6 Vgl. Hermann ZSCHOKKE, Das österreichische Pilgerhaus in Jerusalem, in: Oesterreichische Revue 5 (1867), Heft 1, S. 134-145, hier S. 135. 
Als Generalkommissare der ersten Zeit machten sich besonders verdient: der bereits genannte Spanier P. Petrus Orosco, indem er vom Kaiser ein Schreiben an den Sultan erwirkte, wodurch die Franziskaner die ihnen verlorengegangenen Heiligen Stätten in Jerusalem und Bethlehem wieder erlangten. P. Ludwig Kriechenhoffer, gestorben 1681, fungierte als erster deutscher Generalkommissär. Dritter Generalkommissär von Wien war der eng mit dem Hof Leopolds I. verbundene P. Simon de García. Des weiteren hatten das Amt inne P. Maxentius Eisner aus Passau, ein Gelehrter und Dichter, sowie 37 Jahre lang P. Franziskus Caccia aus Klagenfurt, während dieser Zeit Provinzial der österreichischen Franziskanerprovinz, General-Definitor des Ordens und Hofprediger von Wien. Der gebürtige Wiener P. Hugo Babler war zweimal Provinzial, geistlicher Rat von Gran und Wien sowie Hoftheologe bei Kaiser Karl VI. Unter Marzellian Wagner (1779-1783) kam das vorläufige Ende des Generalkommissariats ${ }^{7}$.

Vor den achtziger Jahren des 18. Jahrhunderts bestand im Franziskanerkonvent in Wien somit eine eigene Einrichtung, die die diesem Orden mit allerhöchsten Reskripten bewilligten Sammlungen zur Unterstützung der Missionen am Heiligen Grab in Jerusalem leitete und die Verrechnung bzw. Versendung der Spenden nach Jerusalem besorgte. 1781 wurden diese Sammlungen im Bereich der Erbländer auf Befehl des Kaisers eingestellt; 1784 wurde das Kommissariat schließlich aufgehoben ${ }^{8}$.

Denn der $»$ Kirchensturm in Österreich $"{ }^{9}$ machte auch vor dem Generalkommissariat des Heiligen Landes nicht halt. Über die Aufhebung des Generalkommissariats verfaßte der betroffene Kommissär P. Marzellian Wagner einen lateinischen Bericht »Catastrophe seu deploranda totius Commissariatus Terrae Sanctae cassatio sub Augustissimo Imperatore Josepho II. « ${ }^{10}$. Aufgrund anonymer Anklageschriften ${ }^{11}$, die an den Kaiser gelangten, sei am 17. August 1783 in der Früh eine Regierungskommission in den Kommissariatsräumen

7 Vgl. P. Pirmin HASENÖHRL, Meine Radio-Rede in Wien gehalten am 1. September 1933, in: Österreichische Pilgerbriefe 3 (1934) S. 13-18, hier S. 14. Hasenöhrl bezeichnete das Generalkommissariat zu Beginn seiner Rede als »ein Stück Alt-Wien«, ibid. S. 13. WASNER, Geschichte des General-Kommissariates von Wien, S. 8-11; 500 Jahre Franziskaner der österreichischen Ordensprovinz. Festschrift zur Gründung der österreichischen Franziskanerprovinz zum hl. Bernardin von Siena durch den hl. Johannes von Capistran im Jahre 1451 [Wien 1950], S. 128.

8 Vgl. Das österreichische Pilgerhaus zu Jerusalem, in: Wiener Diöcesanblatt, Jg. 1863, S. 33-40, hier S. 36.

9 WASNER, Geschichte des General-Kommissariates von Wien, S. 12.

${ }_{10}$ "Die Katastrophe oder die beklagenswerte Aufhebung des gesamten Kommissariats des Heiligen Landes unter dem erlauchtesten Kaiser Joseph II.« (Übersetzung d. A.).

"So auch in: Karl Gf. v. Inzaghi an k.k. geheime Haus-, Hof- und Staatskanzlei, Wien, 1843 Februar 23, in: Haus-, Hof- und Staatsarchiv, Wien (ferner: HHStA), Administrative Registratur (ferner: AR), Fach (ferner: F) 53, Karton (ferner: K) 5. Inzaghi (1777-1856) wurde 1834 in die Vereinigte Hofkanzlei berufen und war seit 1842 Obersthofkanzler. 
erschienen, bestehend aus Regierungsrat Högerlin und seinem Sekretär Schilling. Högerlin habe ein kaiserliches Handschreiben vorgewiesen, womit er beauftragt war, über Verwaltung, Vermögen und Stand des Kommissariats eine genaue Untersuchung vorzunehmen - die Befragung des Generalkommissärs, die Untersuchung aller Räumlichkeiten und die Beschlagnahmung der administrativen Bücher habe insgesamt drei Tage gedauert. Das Verhör des Generalkommissärs habe sich dabei auf folgende Fragen konzentriert: was das Kommissariat dem Konvent für den Unterhalt des Kommissärs bezahle; wieviel Geld jedes Jahr in das Heilige Land abgeführt werde; ob man in Jerusalem mit den Almosen gut wirtschafte; ob der Generalkommissär niemandem Rechenschaft zu geben habe (darauf habe dieser erwidert, daß er jährlich dem Provinz-Definitorium einen Rechenschaftsbericht vorlege); des weiteren ob vielleicht im Kommissariat öfters Festtafeln stattfänden, zu denen auch auswärtige Gäste geladen würden, was Wagner mit Entrüstung zurückgewiesen habe $^{12}$. Nach Revision der Geschäftsbücher habe Högerlin abschließend die Frage gestellt, ob der in den Büchern ausgewiesene Überschuß tatsächlich vorhanden sei. Die im Kommissariat beschäftigten Männer, neben Generalkommissär Wagner sein Sekretär P. Chrysolog Paradeiser, der Tertiar Fr. Karl und der apostolische Syndikus Herr Pach, mußten einen Eid ablegen, daß sie nichts verheimlicht hatten. Anschließend seien auch die beiden damals noch lebenden Ex-Kommissäre - P. Cyprian Palm und P. Humilis Ermblich - wie auch der Ex-Kustos der Provinz, P. Gratian Klappitz, zum Verhör gerufen worden. Am 19. August sei die Untersuchung des Generalkommissariats zum Abschluß gekommen, und zwar mit Lob von seiten Högerlins, der öffentlich erklärt habe, alles in bester Ordnung gefunden zu haben, was er auch in seinem Bericht an den Kaiser hervorheben werde. Für den weiteren Fortbestand des Kommissariats sei nichts zu befürchten, es sei denn, daß von den kaiserlichen Konsuln in Palästina eine verschwenderische Geldgebarung des P. Prokurators in Jerusalem gemeldet würde. Dennoch müsse er mittlerweile »jede Abgabe von Gegenständen und Geld an das H1. Land verbieten, bis eine Entscheidung Sr. Majestät erflossen sein werde«. P. Marzellian schrieb daraufhin an den Kustos und an den Prokurator, um sie über die Gefahr der Aufhebung des Kommissariats zu informieren.

Um diese Zeit waren gerade die sieben Jahre abgelaufen, nach welchen der Ordnung gemäß die Sammlung für das Hl. Land in Belgien (damals zu Österreich gehörig) hätte beginnen müssen. Ich reichte darum bei Sr. Majestät meine Bittschrift ein, um die nötige Erlaubnis zu erhalten. Aber - wie vorauszusehen - ich wurde abgewiesen. Als Ursache wurde mir von einer Persönlichkeit des Hofes mitgeteilt, daß nach Ansicht des Kaisers zuviel Geld aus den

${ }^{12}$ Der damals gegen das Generalkommissariat erhobene Vorwurf von Mißständen war im Gedächtnis des 19. Jahrhunderts noch sehr präsent, was große Auswirkungen auf seine 1843 formulierten Statuten haben sollte, mit denen man sich deutlich von dem früheren Modell abzugrenzen suchte. 
österreichischen Provinzen durch das Kommissariat in das Hl. Land abgeführt werde, wofür gar kein Nutzen für Österreich zu hoffen sei. Wie ich dies erfuhr, verfaßte ich sofort eine neue Bittschrift an den Kaiser, in welcher ich darlegte, daß nur ein Teil der Gelder ins Hl. Land abgeschickt werde, ein anderer jedoch zu Anschaffungen für die Bedürfnisse der Terra Santa verwendet werde, was ja der heimischen Industrie und Kunst zugute komme. Aber alles war umsonst, ich erhielt nicht einmal eine Antwort auf meine Eingabe.

Am 10. Mai 1784 wurde dem Wiener Konvent mitgeteilt, daß das Generalkommissariat des Heiligen Landes aufgrund des allgemeinen Sammlungsverbotes aufgehoben und sein gesamtes Vermögen dem Religionsfonds zu übergeben sei, zu welchem Zweck Christian von Wallenfeld demnächst im Kloster erscheinen werde ${ }^{13}$. Aus dem Hauptteil des vorhandenen Vermögens, und zwar aus 107700 fl., »welcher Summe ein Minister noch 12,000 fl. hinzufügte«, wurde im Jahr 1785 der »Sustentationsfonds« für die bosnische Mission gegründet ${ }^{14}$.

Das Generalkommissariat war mit kaiserlicher Entschließung vom 30. April 1784 aufgehoben worden; weiters wurde bestimmt, daß spezielle, weiterhin für das Heilige Grab zu verwendende Gelder durch die k.k. Geheime Hof- und Staatskanzlei an den Internuntius und durch diesen dem »Commissarius terrae sanctae in Konstantinopel zu übergeben seien: »Von da an hörte der Einfluß der Franziskaner in den alt österreichischen Provinzen auf dieses Geschäft auf [...].« Der Ausnahmestatus zweier Kronländer ist in diesem Zusammenhang zu beachten, denn in Lombardo-Venetien und Dalmatien bestanden derlei Sammlungen weiter, und Kaiser Franz sanktionierte ihren Weiterbestand auch für die Zukunft. »Die dort eingegangenen Gelder wurden sonach bis zum Jahre 1842 ohne Intervenirung einer Behörde unmittelbar aus den betreffenden Provinzen an den Ort ihrer Bestimmung gesendet. Es mußte jedoch hieher ausgewiesen werden, was alle Jahre eingeht. ${ }^{15}$

Nach einigen Tagen wurde schließlich auch das Kommissariatsarchiv mitsamt der Bibliothek fortgeschafft, und die Räume wurden gesperrt. 1802 wurde der ehemalige Amtstrakt des Generalkommissariats von der Regierung mit

${ }^{13}$ Eine ausführliche Schilderung der Vorgänge rund um die Aufhebung findet sich in: WASNER, Geschichte des General-Kommissariates von Wien, S. 12-15, Zitate S. 14f. Laut P. Marzellian Wagner umfaßte das beschlagnahmte Vermögen: $34200 \mathrm{fl}$. an Bargeld, $110000 \mathrm{fl}$. an Obligationen und Kapitalien, $30800 \mathrm{fl}$. an frommen Stiftungen, $5600 \mathrm{fl}$. an Wertgegenständen, die für das Heilige Land besorgt worden waren. Ibid. S. 16. Der Generalkommissär wurde noch einige Male in Sachen Generalkommissariat beim Kaiser vorstellig, der aber bei seiner Entscheidung blieb. Im Wiener Diözesanarchiv findet sich eine Abschrift des 1844 auf Deutsch veröffentlichten Berichtes von Wagner: "Austria oder Oesterreichischer Universal-Kalender für das Schaltjahr 1844. Wien. [...] Religiöses und kirchliches Leben. Die Sammlungen für das heilige Grab«, Abschrift, in: Diözesanarchiv Wien (ferner: DAW), Präsidialia I 6, Österr. Pilgerhaus in Jerusalem, Kassette 1.

14 ZSCHOKKE, Das österreichische Pilgerhaus in Jerusalem, S. 135.

${ }^{15}$ Karl Gf. v. Inzaghi an k.k. geheime Haus-, Hof- und Staatskanzlei, Wien, 1843 Februar 23, in: HHStA, AR, F 53, K 5. 
Beschlag belegt und für einige Abteilungen der Hofstelle verwendet, wodurch »selbst die Erinnerung an das Kommissariat fast verloren " ging ${ }^{16}$. Österreich hatte »den Verband, welchen es Jahrhunderte hindurch mit der Custodie des heil. Landes und den ihr unterstehenden Missionen unterhalten hatte, durch Aufhebung des General-Commissariates und Einstellung der Collecten selbst gelöst « ${ }^{17}$.

\section{Palästina im Blickfeld Europas - ein Neubeginn}

Vor dem Hintergrund der Reformentwicklungen im Osmanischen Reich Stichwort Tanzimat -, die es den Europäern zusätzlich zu ihren in den »Kapitulationen « seit langem festgeschriebenen Rechten realpolitisch gesehen ermöglichten, ihre dortigen Einflußsphären mehr und mehr auszudehnen, entzündete ein dichtes Bündel an Faktoren erneut den Funken der »Palästinabegeisterung « und lenkte die Aufmerksamkeit der europäischen Öffentlichkeit wieder auf die Region Naher Osten: Weltpolitische Ereignisse (ausgehend vom napoleonischen Feldzug 1799 über die ägyptische Herrschaft 1831-1840 und ihre Auswirkungen, gipfelnd in den Ereignissen rund um den Londoner Vertrag 1840) trafen zusammen mit kirchenpolitischen Maßnahmen und einer Vielzahl von geistesgeschichtlichen Strömungen, darunter die Romantik, die Idee des »friedlichen Kreuzzugs« und das allgemeine Missionsinteresse nicht ohne Grund wurde das 19. Jahrhundert von »einschneidender Bedeutung für die Entwicklung und Gestaltung der Orientmission ${ }^{18}$. Ein kirchenpolitischer Schritt, von dem eine geradezu als elektrisierend zu bezeichnende Wirkung auf die katholische Kirche ausging, war die Gründung eines anglopreußischen Bistums in Jerusalem 1841; auf staatlicher Vertretungsebene setzten sich europäische Konsuln in Jerusalem fest.

Das Konzept des »friedlichen Kreuzzugs«, von dem das katholische Europa mittlerweile überzogen wurde, griff zurück auf das »Goldene Zeitalter« des Christentums, das Mittelalter:

Um [die] Mitte des 19. Jahrhunderts verminderten [sich] oder verschwanden die äußeren und inneren Hindernisse, die der Pilgerung nach dem heiligen Lande gegenüber standen. [...] Jetzt bricht eine neue Epoche an in Palästina, das Zeitalter des friedlichen Kreuzzugs. Nicht wie ehedem, durch Blut und Eisen soll das Land erobert werden, sondern durch fried-

${ }^{16} \mathrm{Vgl}$. HASENÖHRL, Meine Radio-Rede in Wien, S. 16.

${ }^{17}$ ZSCHOKKE, Das österreichische Pilgerhaus in Jerusalem, S. 135.

${ }^{18}$ Konrad LÜBECK, Die katholische Orientmission in ihrer Entwicklung dargestellt, Köln 1917, S. 13. 
liche Kultur. An Stelle der bewaffneten Krieger treten die christlichen Pilger aus allen Ländern Europas'.

Diese Idee ist im Rahmen einer besonders ausgeprägten »JerusalemFrömmigkeit« zu verstehen, verbunden mit religiös begründeten Heimatgefühlen und Ansprüchen, denn: "Keine Stadt der Erde übt eine solche Anziehungskraft aus wie Jerusalem. Jeder Christ hat von dieser Stadt und ihrer Umgebung sammt allen Einzelheiten von der ersten Kindheit an gehört. ${ }^{20}{ }^{20}$

Im Fall Österreichs ging die Kirche mit ihren Initiativen dem Staat zeitlich voraus, obwohl freilich ein untrennbares Zusammenwirken und -gehen dieser beiden Säulen der Monarchie zu konstatieren ist. Sowohl am Zustandekommen der neuerlichen Genehmigung der Karwochenkollekte für die Heiligen Stätten und der Wiedererrichtung des Generalkommissariats wie auch der Eröffnung eines österreichischen Vizekonsulats in Jerusalem $1849^{21}$, genehmigt durch Kaiser Ferdinand I., kann der Anteil eines Mannes nicht genug hervorgehoben werden: des Domkapitulars zu St. Stephan, Joseph Salzbacher.

Salzbacher wies bereits anläßlich seiner im Jahr 1837 unternommenen Pilgerreise nach Rom und Jerusalem auf den finanziellen Notstand der Franziskaner im Heiligen Land hin und stellte die Konflikte zwischen "Lateinern" und »Griechen« um die Heiligen Stätten dar $^{22}$. Er machte sich zum engagierten Lobbyisten für sein auch in Politik und Mentalität der Zeit auf fruchtbaren Boden fallendes Anliegen und führte diesbezüglich Unterredungen mit Staatskanzler Metternich. Salzbacher selbst schildert:

Da ich schon früher Sr. Durchlaucht dem Herrn Staatskanzler (Fürsten von Metternich) das abschriftliche Document aus dem Memorabilienbuche des hiesigen Franziskanerklosters ad S. Hieronymum, welches die unter der Regierung Sr. Majestät des Kaisers Joseph höchstse-

${ }^{19}$ Karl SCHNABL, Die Babenberger und Habsburger im heiligen Lande, in: Jahrbuch des österr.-ung. Pilgerhauses »Zur heiligen Familie« in Jerusalem, hg. vom Kuratorium, Jg. 4, Wien 1911, S. 25-34, hier S. 33f. Siehe zum wfriedlichen Kreuzzug« auch Alexander SCHÖLCH, Palästina im Umbruch 1856-1882. Untersuchungen zur wirtschaftlichen und sozio-politischen Entwicklung (Berliner Islamstudien, 4), Stuttgart 1986, S. 64-68.

${ }^{20}$ Johann WEISS, Reise nach Jerusalem und Wanderungen im heiligen Lande. Dem katholischen Volke erzählt (Zweite Vereinsgabe des Katholischen Pressvereines in der Diöcese Seckau für das Jahr 1902), Erster Theil, Graz 1902, S. 88.

${ }^{21} \mathrm{Zu}$ den Aktivitäten der österreichisch(-ungarisch)en Konsuln in Jerusalem siehe Mordechai ELIAV unter Mitarbeit von Barbara HAIDER (Hg.), Österreich und das Heilige Land. Ausgewählte Konsulatsdokumente aus Jerusalem 1849-1917 (Fontes rerum Austriacarum, 2. Abt., Bd. 91), Wien 2000.

${ }^{22} \mathrm{Vgl}$. Joseph SALZBACHER, Erinnerungen aus meiner Pilgerreise nach Rom und Jerusalem im Jahre 1837, 2 Bde., Wien 1839. Der Ertrag aus diesem bereits 1840 in zweiter Auflage erscheinenden Werk war mit kaiserlicher Bewilligung als Almosen für das Heilige Grab gewidmet. Siehe zu dem 1790 in St. Pölten geborenen und am 10. August 1867 in Baden verstorbenen Salzbacher, seit 1847 insulierter Prälat und Domkustos bei St. Stephan in Wien, 1862 von Kaiser Franz Joseph mit dem Orden der eisernen Krone ausgezeichnet, den von Hermann ZSCHOKKE verfaßten Nachruf: Zur Erinnerung an den Domcustos Dr. Joseph Salzbacher, in: Das heilige Land 12 (1868) S. 27-29. Salzbachers Interesse richtete sich anschließend auch auf die Mission in Nordamerika. 
ligen Andenkens, decretirte Aufhebung des schon seit vielen Jahren bestehenden GeneralCommissariates der heiligen Länder in Wien, und die Einziehung der damals in der Cassa vorhandenen Baarschaft im Betrage von mehr als 180,000 Gulden in Gold, Silber und Obligationen u.s.w. unterbreitet und auch noch Andere, welchen dieser Vorgang ganz unbekannt war, davon in Kenntniß gesetzt hatte, - leitete der Gedanke von selbst auf die Resuscitirung des ehemaligen General-Commissariates, und es begannen die diesfalls nöthigen Verhandlungen von Seiten der betreffenden Behörden, so wie der kaiserlichen General-Consulate in Aegypten und Syrien, von welchem Letztern insbesondere Berichte, und eine getreue Schilderung über die Lage und Verhältnisse unserer Missionen im Oriente abgefordert wurden ${ }^{23}$.

Alle finanziellen Rücksichten letztlich doch beiseite lassend, wurde das offizielle Österreich durch die Beobachtungen von Salzbacher wie auch durch die später von Johann Mosetizh durchgeführten Erkundungen ${ }^{24}$ dazu bewogen, im Rahmen der Reorganisierung seines Konsularwesens in Syrien eine Vertretung in Jerusalem einzurichten. Als Besonderheit ist dabei hervorzuheben, daß

nicht kommerzielle Beweggründe maßgebend [waren], sondern die Würde des österreichischen Staates erheischte es, daß Österreich bei Vertretung der Interessen der katholischen Kirche mit den übrigen Großmächten [...] gleichen Schritt halte, besonders zu einer Zeit, in welcher die Schismatiker, namentlich Rußland, die Katholiken aus dem Heiligen Lande zu verdrängen suchten. Dazu kam das lebhafte Interesse der Katholiken Österreichs für das Heilige Land und der beginnende größere Zuzug von Pilgern nach Palästina. [...] anderseits jedoch rief die Existenz eines österreichischen Konsulates den katholischen geistlichen Hütern der heiligen Stätten in Erinnerung, daß nicht nur Frankreich, sondern auch Österreich hinter ihnen stehe ${ }^{25}$.

Der erste Amtsinhaber in Jerusalem, Josef (Giuseppe) Graf von Pizzamano ${ }^{26}$, in dessen Amtszeit die Erhebung des Vizekonsulats zum Konsulat (1852) und die Anfänge des österreichischen Hospizes fielen, stellte sich dabei sogleich als höchst energischer Vertreter der österreichischen Interessen heraus.

${ }^{23}$ Joseph Salzbacher, in: Austria (1856), zit. nach: Das General-Commissariat der heiligen Länder, in: Das heilige Land 1 (1857) S. 115-119, hier S. 116. Vgl. zum Bericht des k.k. Generalkonsuls in Beirut, Eduard von Adelburg, auch ZsCHOKKE, Das österreichische Pilgerhaus in Jerusalem, S. 136.

${ }^{24}$ Siehe dazu weiter unten. Metternich stützte sich in seiner Argumentation hinsichtlich der Errichtung eines Konsulats in Jerusalem explizit auf die Denkschrift von Mosetizh, vgl. Vortrag Metternichs an Kaiser Ferdinand (Wien, 1846 Februar 24), in: ElIAV, HAIDER (Hg.), Österreich und das Heilige Land, S. 101-103.

${ }^{25}$ Einleitung, in: Jahrbuch des österr.-ungar. Pilgerhauses »Zur heiligen Familie« in Jerusalem, hg. vom Kuratorium, Jg. 1, Wien 1905, S. 1-4, hier S. 4. Siehe auch die hinsichtlich der Motivation Metternichs sehr aufschlußreiche Instruktion für den ersten Vizekonsul Pizzamano (Constantinopel, 1849 Jänner 9), in: ELIAV, HAIDER (Hg.), Österreich und das Heilige Land, S. 107-110.

${ }^{26}$ Siehe zu dem 1809 in Venedig geborenen und mit kaiserlicher Entschließung vom 27. September 1847 zum Vizekonsul in Jerusalem ernannten Josef (Giuseppe) von Pizzamano, der Jerusalem jedoch erst am 1. März 1849 erreichen solite: ELIAV, HAIDER (Hg.), Österreich und das Heilige Land, bes. S. 47-64. 


\section{Die Wiedereinführung der Karwochenkollekte}

Bei der Reaktivierung der Karfreitagskollekte und des Generalkommissariats für das Heilige Land konzentrierten sich die Absichten zuallererst und vor allem auch im Hinblick auf die immer stärker werdende Konkurrenz unter den verschiedenen Religionsgemeinschaften im Heiligen Land auf die Beschaffung der nötigen Missionsmittel für bestimmte Zwecke der - einer Stärkung der Position der katholischen Großmacht Österreich zuträglichen - Orientmission. Die Karfreitagskollekte zur Unterstützung der Franziskaner im Orient ging dabei auf frühere Jahrhunderte zurück; so hatte unter anderem schon Papst Pius VI. im Jahr 1778 bestimmt, daß alle Bischöfe ihre Gläubigen viermal im Jahr auffordern sollten, die Orientmission durch Spenden zu unterstützen ${ }^{27}$.

Die ersten beiden Kronländer, denen die Durchführung von Sammlungen für das Heilige Land wieder gestattet wurde, waren Lombardo-Venetien und Dalmatien (mit allerhöchster Entschließung vom 19. August 1815 bzw. 18. März 1837). Mit kaiserlichem Handschreiben vom 21. Februar 1842 - angeregt durch Joseph Salzbachers Aufruf und die politischen Ereignisse im Orient sind diese Sammlungen

auch in den altösterreichischen Ländern wieder in's Leben gerufen worden. Se. k.k. apost. Majestät sprachen nämlich in diesem Handschreiben den allerh. Willen aus, daß die für das lombardisch-venetianische Königreich und für Dalmatien bereits bestehende Bewilligung zu Gunsten der bedrängten katholischen Missionen am h. Grabe auf alle der Leitung der (damaligen) Vereinigten Hofkanzlei unterstehenden Provinzen in der Art ausgedehnt werde, daß die Erzbischöfe und Bischöfe ermächtiget werden, die Gläubigen jährlich an einem Sonntage in der Faste, oder auch, wenn sie es dienlicher finden, am Charfreitage zu Beiträgen für die oben genannten Missionen aufzufordern ${ }^{28}$.

Das Ergebnis der ersten Sammlung belief sich auf $51623 \mathrm{fl}$. Aus der Wiedereinführung der Karwochenkollekte resultierte konsequenterweise auch die Wiedererrichtung des Generalkommissariats, das ja unter anderem als Verwaltungsstelle für die einlaufenden Gelder fungierte. »Damit aber bei Herstellung des General-Commissariates künftigen Uebelständen und Mißbräuchen vorgebeugt werde, wurde dem Fürst-Erzbischof von Wien die Aufgabe zu Theil, Statuten zu entwerfen, welche die vorzunehmenden Abänderungen und den ganzen Wirkungskreis des Commissariates zu bestimmen hatten. ${ }^{29}$

Bis Ende des Jahres 1843 wurden somit von Vinzenz Eduard Milde 21 Paragraphen umfassende "Grundregeln und Vorschriften für das General-

${ }^{27} \mathrm{Vgl}$. Bernard ARENS, Handbuch der katholischen Missionen, 2., vollständig neubearbeitete Aufl., Freiburg im Breisgau 1925, S. 283.

${ }^{28}$ Das österreichische Pilgerhaus zu Jerusalem, in: Wiener Diöcesanblatt 1863, S. 36f., Zitat S. 37. Ibid. S. 37-40 findet sich eine lateinische Version der "Grundregeln und Vorschriften für das General-Commissariat der heiligen Länder«: »Leges fundamentales et regulae Commissariatus generalis terrae sanctae $\ll$.

${ }^{29}$ ZSCHOKKE, Das österreichische Pilgerhaus in Jerusalem, S. 136. 
Commissariat der heiligen Länder « ${ }^{30}$ ausgearbeitet, in deren Präambel die kaiserliche Entschließung vom 21. Februar 1842 betreffend die in allen Pfarren der Monarchie durchzuführenden Sammlungen für das Heilige Grab festgehalten ist.

\section{Das neue Generalkommissariat}

Die Wiedererrichtung des Wiener Generalkommissariats wurzelte nicht nur in der Initiative Salzbachers, sondern eine entsprechende Anregung kam auch aus den Reihen der Franziskaner - der damalige Franziskaner-Guardian P. Becker richtete eine Eingabe an den Kaiser ${ }^{31}$.

Den Anregungen aus den Reihen des Wiener Klerus folgten Verhandlungen zwischen der Vereinigten Hofkanzlei und der Geheimen Haus-, Hof- und Staatskanzlei, wobei auch der Wiener Erzbischof um seine Meinung gefragt wurde $^{32}$. Die Hofkanzlei spürte zunächst mit einem Fragenkatalog der Geschichte der Sammlungen für das Heilige Land und des früheren Kommissariats nach und kam zu dem Schluß, daß nicht übersehen werden dürfe, »daß der dermalige Stand der Dinge wesentlich von jenem verschieden ist, der bis zur Aufhebung jenes Kommissariats bestand«. Während die Franziskaner das Geld damals selbst gesammelt und nach Jerusalem getragen hätten, würden es nun die Ordinariate sammeln, und der Wiener Konvent sollte, "wenn die in der [...] Eingabe des P. Guardian besprochenen Modalitäten die Allerhöchste Genehmigung erhalten, nur die Kassaführung haben, die Uibersendung [!] der Gelder sollte dennoch durch die löbliche k.k. geheime Hof- und Staatskanzlei nach dem Oriente geschehen «. Das alte Kommissariat sei infolge verschiedener aufgetretener Mißbräuche aufgehoben worden, weshalb bei seiner neuerlichen Konstituierung für eine entsprechende Kontrolle Vorsorge zu treffen sei.

${ }^{30}$ Grundregeln und Vorschriften für das General-Commissariat der heiligen Länder, Wien, 1843 December 16, in: HHStA, AR, F 53, K 5. Alle Paragraphen der »Grundregeln«, auf die im folgenden Bezug genommen wird, sind diesem Dokument entnommen.

${ }^{31}$ Vgl. unter anderem: Zur Geschichte des österreichisch-ungarischen Hospizes in Jerusalem, in: Protokoll der bischöflichen Versammlung in Wien vom 23. bis zum 27. November 1897. Sammt Beilagen, Prag 1898, S. 121f., hier S. 121, in: DAW, Bischofskonferenzen (ferner: BIKO), Karton 8, 1887-1900.

${ }^{32} \mathrm{Karl}$ Gf. v. Inzaghi an k.k. geheime Haus-, Hof- und Staatskanzlei, Wien, 1843 Februar 23, in: HHStA, AR, F 53, K 5. Aus diesem Dokument wird offensichtlich, daß die ersten Vorstellungen von seiten der Franziskaner, des Wiener Erzbischofs und der Hofkanzlei noch ziemlich stark von der später erfolgten tatsächlichen Ausführung des neuen Generalkommissariats divergierten. Die Ansichten Mildes, der sich von Anfang an eine starke Position sichern wollte und eine deutliche Oppositionshaltung gegenüber den Vorschlägen der Franziskaner einnahm, waren in vielem ausschlaggebend. 
Da der bisher bedeutendste Sammelbetrag aus Niederösterreich eingegangen sei, habe man zunächst den Wiener Fürsterzbischof um seine Meinung fragen müssen. Erstens sei somit zu diskutieren, ob das ehemalige Kommissariat und damit die Intervention des Wiener Franziskanerkonvents sunter entsprechenden Vorsichtsmaßregeln « wieder ins Leben treten dürfe. Fürsterzbischof Milde habe sich gegen die Anträge des P. Becker, der inzwischen nicht mehr Guardian sei und dessen Schrift daher nur als »Privatversuch« anzusehen sei, ausgesprochen; der hiesige Franziskanerkonvent stehe mit den Franziskanern am Heiligen Grab in Jerusalem zudem auch in keiner Verbindung. Der Fürsterzbischof meine daher, daß bei dem veränderten Stand der Dinge jede Intervention des Wiener Franziskanerkonvents bei der Sammlung und Übersendung der Spenden für die Missionen am Heiligen Grab unangemessen wäre, welcher Ansicht sich die Vereinigte Hofkanzlei anschließe: "Es darf nicht übersehen werden, daß die eingegangenen Gelder aus allen Provinzen der österreichischen Monarchie herstammen, denen der hiesige Franziskanerkonvent ganz fremd ist.« Auch müßten die besonderen Verhältnisse von Lombardo-Venetien und Dalmatien wie auch jene von Ungarn und Siebenbürgen, »aus welchen auch Gelder eingegangen sind «, beachtet werden.

Zweitens habe der Fürsterzbischof folgende Vorschläge gemacht: "Die in dem heil. Lande nicht nur in Jerusalem, sondern auch die zu Bethlehem, Nazareth, Ramla, St. Johann u.s.w. befindlichen Franziskaner bedürfen dringend einer jährlichen Unterstützung; denn sie haben keine bestimmte jährliche Dotation; die ehemaligen Zuflüsse aus Frankreich, Spanien, Portugal haben ganz aufgehört, die Klöster sollen die Pilger verpflegen, die armen Katholiken unterstützen und haben oft sehr bedeutende Abgaben zu entrichten.« Eine Unterstützung der Katholiken sei um so notwendiger, als die »Griechen« mächtige Unterstützung durch Rußland erfahren und sich durch ihr Geld die Gunst der Türken erwerben würden. Wenn man die Franziskaner nicht unterstütze - was nur durch Sammlungen aus Europa möglich sei -, sei zu befürchten, daß sie ganz vertrieben würden.

»Der Fürsterzbischof erklärt jedoch ferners, daß durch Geldsendungen, wären sie auch noch so bedeutend, dem religiösen Zustande im heiligen Lande nicht abgeholfen werde, wenn man nicht zugleich einem andern, eben so wichtigen Mangel abzuhelfen trachte." Denn in den Klöstern in Jerusalem, Bethlehem und Nazareth bestünden die Franziskaner zur einen Hälfte aus Italienern, zur anderen Hälfte aus Spaniern. In Jaffa, Ramla und St. Johann befänden sich nur Spanier, in den übrigen Klöstern nur Italiener. Unter den rund 40 Priestern in Jerusalem finde sich ein einziger, der notdürftig deutsch verstehe, und keiner, der französisch oder eine slawische Sprache spreche. Aus Frankreich könnten, da der Orden dort nicht mehr bestehe, keine Franziskaner kommen, "folglich kann nur aus Deutschland dem Bedürfnisse der genannten Sprachen abgeholfen werden«. Bis 1783 seien stets einige Franziskaner aus Österreich 
als Missionäre in Jerusalem vorhanden gewesen. »Der Fürsterzbischof macht daher den Antrag, daß wieder einige fromme Priester des Ordens aus den österreichischen Franziskaner-Provinzen nach dem heiligen Lande abgesendet werden.« Dafür sei aber ein Zentrum nötig, »welches durch Ernennung eines ausgezeichnet frommen Franziskaner-Priesters, ohne Rücksicht auf die Provinz, der er angehört, zum Commissarius terrae sanctae, der stets in Korrespondenz und Verbindung mit dem in Konstantinopel befindlichen Commissario und mit dem Discretorio der Klöster im heiligen Lande gefunden werden könnte«.

Das Kommissariat müßte alle Franziskanerprovinzen der Monarchie umfassen, aus denen Priester - für sechs bis acht Jahre - nach Jerusalem entsandt werden könnten. "Da der Sitz des Kommissärs di terra santa allzeit in Wien sein müßte, so dürfte nach der Ansicht des Fürsterzbischofs der jeweilige Erzbischof von Wien vorzüglich dazu geeignet und anzugehen sein, [...] die mit dem Protektorate verbundene Mühe zu übernehmen. « Der jeweilige Protektor hätte sich dabei stets mit den Provinzialen ins Einvernehmen zu setzen. Obersthofkanzler Inzaghi schloß sich dieser Meinung des Fürsterzbischofs vollinhaltlich an. Neben der Wiener Provinz halte man insbesondere die Franziskaner der Provinzen Böhmen und Mähren, Illyrien und Tirol für geeignet; man übergehe dabei Galizien wie auch Lombardo-Venetien und Dalmatien (letztere, "weil es an Italienern in Jerusalem nicht fehlt«). Vorsorge müßte für die jeweils nötige Ergänzung der österreichischen Franziskaner und die Verwaltung der eingehenden Gelder getroffen werden. Im Gegensatz zu P. Becker habe sich der Fürsterzbischof jedenfalls gegen die Kapitalisierung der eingegangenen Gelder und gegen die Fundierung eines unangreifbaren Fondskapitals ausgesprochen, da es auf die hiesigen Gläubigen und auf die Franziskaner im Heiligen Land einen sehr ungünstigen Eindruck machen würde, wenn man einen großen Teil der Sammlungsgelder zurückhalte. - Auch in dieser Hinsicht stimme man den Ansichten des Fürsterzbischofs bei; nunmehr sei es notwendig, »wegen Konstituirung des vom Fürsterzbischofe vorgeschlagenen Kommissariats, Protektorats und wegen Entsendung der Priester ins Ausland die A.h. Genehmigung Sr. Majestät einzuholen«. Zunächst seien entsprechende Regeln vonnöten, „damit wenigstens mittlerweile die Allerhöchste Absicht Seiner Majestät, dem gelobten Lande aufzuhelfen, erreicht werde«. Die k.k. Vereinigte Hofkanzlei meine daher, daß die k.k. Geheime Haus-, Hof- und Staatskanzlei sofort $8000 \mathrm{fl}$. für die Missionen am Heiligen Grab absenden solle. Des weiteren könnten die aus Lombardo-Venetien und Dalmatien eingegangenen Gelder wie bisher unmittelbar nach Palästina gesandt werden. Der auf diese Weise zu erzielende Gesamtbetrag wäre für das laufende Jahr ausreichend. Abschließend bat die Vereinigte Hofkanzlei die Geheime Hof- und Staatskanzlei um Bekanntgabe ihrer Ansichten zu den vorliegenden Anträgen, um danach Kaiser Ferdinand Vortrag erstatten zu können. 
Wieder wurde die Sonderstellung Lombardo-Venetiens und Dalmatiens betont. Die in Lombardo-Venetien eingegangenen Sammelgelder wurden gemäß kaiserlicher Genehmigung vom 22. Februar 1843 an den Provinzial des Franziskanerordens in Venedig weitergeleitet, der das Geld als Lokal-Kommissär direkt an den Kustos in Jerusalem übersandte und seine Verwaltung durch einen jährlichen Spezialausweis rechtfertigte. Als man jedoch - um eine größere Einheit zu erlangen - die Vereinigung der italienischen Provinzen mit dem Generalkommissariat in Wien durchführen wollte und ein Ministerialdekret vom 15. Februar 1852 die frühere Ausnahmestellung aufgehoben hatte, wurde jener Beschluß aufgrund einer Gegendarstellung des Kommissärs in Venedig und aufgrund Bitten der Kustodie mit Dekret vom 22. Oktober 1852 wieder zurückgenommen, "mit Rücksicht darauf, daß der Bestand jenes LokalKommissariats in Venedig wegen leichter Versendung von Effekten und Viktualien sich als zweckgemäß, ja notwendig erwies. Gleichzeitig jedoch wurde dieses Kommissariat dem Generalkommissariat in Wien als Filiale unterstellt. ( $^{33}$

Die Hofkanzlei erstattete am 25. April 1843 Vortrag an den Kaiser, dessen Entschließung vom 13. Juni 1843 neben einer Anordnung über die Verwendung der Gelder und der Genehmigung der Errichtung eines Generalkommissariats den Befehl enthielt, vom Wiener Erzbischof ein Gutachten über dessen Bildung, Modalitäten, Umfang und Wirksamkeit abzuverlangen. Nach einem neuerlich erstatteten Vortrag genehmigte der Kaiser mit Entschließung vom 14. November 1843 die vorgelegten Statuten des Generalkommissariats, die einen Monat später - unter dem 16. Dezember - veröffentlicht wurden ${ }^{34}$. Somit waren gegen Ende des Jahres 1843 die Grundlagen für die Aktivitäten des Generalkommissariats in den folgenden Jahrzehnten gelegt.

Die wesentlichsten Änderungen in der Struktur des neu errichteten Generalkommissariats, verstanden als Sicherheitsmaßnahmen, bestanden neben der Unterstellung unter das Protektorat des jeweiligen Wiener Erzbischofs vor allem in zwei Punkten: Die Kollekten wurden ab nun durch die bischöflichen Ordinariate - und nicht wie früher durch Ordenspriester - veranstaltet, und die Sammelbeträge sollten ausschließlich für bestimmte Zwecke verwendet und nicht der willkürlichen Disposition der Empfänger überlassen werden ${ }^{35}$.

${ }^{33}$ ZSCHOKKE, Das österreichische Pilgerhaus in Jerusalem, S. 137.

${ }^{34} \mathrm{Vgl}$. Grundregeln und Vorschriften für das General-Commissariat der heiligen Länder (wie Anm. 30); teilweise unkorrekt die Darstellung des Ablaufes in: Das GeneralCommissariat des heiligen Landes in Wien, in: Denkblatt des österreichisch-ungarischen Pilgerhauses, S. 6.

${ }^{35} \mathrm{Vgl}$. ZsCHOKKE, Das österreichische Pilgerhaus in Jerusalem, S. 137. 


\section{Die Wiener Generalkommissäre}

Mit der Bestätigung von P. Joseph Matzek in der Funktion des Generalkommissärs durch den Kaiser am 19. März 1844 und seinem Amtsantritt am 30. Mai "war der Verband Österreichs mit den katholischen Missionen Palästinas wieder hergestellt $\aleph^{36}$, und die jährliche Rechnungslegung sollte den Zeitgenossen aufzeigen, »dass durch die erneuerte Theilnahme des österreichischen Kaiserstaates in dem Fortgange der Missionen in den Heiligen Ländern bedeutende Erfolge erzielt wurden ${ }^{37}$.

Das neue Generalkommissariat bestand aus einem Generalkommissär, einem Vizekommissär, dem Klostersyndikus und zwei Assistenten. Die Bestimmungen hinsichtlich der personellen Zusammensetzung des Generalkommissariats sind in den Paragraphen 3 sowie 5 bis 8 der "Grundregeln und Vorschriften " enthalten: "Um die Verwendung der gesammelten Geldbeträge und die Absendung der Missionäre zweckmäßig zu leiten, soll in Wien ein Commissariat der heiligen Länder errichtet werden. Dieses Commissariat soll aus einem General-Commissär, einem Vice-Commissär, dem Wiener-Kloster-Syndicus und zwey Assistenten bestehen. $(§ 3)$ - Die Einsetzung von vier Personen neben dem Generalkommissär ist sicherlich auch als eine der gegen einen eventuellen Mißbrauch gerichteten Anordnungen und Maßnahmen zu sehen. Die »Grundregeln und Vorschriften « enthalten des weiteren nähere Details zu den verschiedenen Ämtern, so sollte die Position des General- und des Vizekommissärs nur von Priestern aus dem Franziskanerorden bekleidet werden können ( 5 5). $\S 6$ hielt fest, daß der Generalkommissär stets vom Wiener Erzbischof bestimmt werden mußte und der Bestätigung durch den Kaiser bedurfte. »Derselbe wird für die Dauer seines Lebens gewählet, wenn er nicht durch Alter, Krankheit oder andere Umstände zur Führung des Amtes unfähig werden sollte.« $\S 7$ bestimmte hinsichtlich des Vizekommissärs, der auf Vorschlag des Generalkommissärs und nach Einvernehmen mit den Vorgesetzten des Vorgeschlagenen ebenfalls vom Erzbischof bestellt wurde, daß er den Generalkommissär in Verhinderungsfällen zu vertreten und jene Geschäfte zu besorgen habe, »die dieser ihm übertragen wird «. $\S 8$ beschäftigt sich mit dem Syndikus und den Assistenten: Der Syndikus des Wiener Franziskanerklosters war, wie üblich, vom Kloster zu wählen. (Er war somit als einziger kraft seines Amtes innerhalb des Klosters Mitglied des Generalkommissariats.) Als Assistenten werde der Erzbischof vorzugsweise »solche Männer wählen, die in dem heiligen Lande als Missionäre zur Zufriedenheit gedienet haben«. Vizekommissär und Assistenten soliten aus allen Klöstern der Österreichischen Monarchie nach Vorschlag der Provinziale auf drei Jahre ausgewählt werden, konnten aber nach deren Ablauf wieder bestätigt werden.

${ }^{36}$ Einleitung, in: Jahrbuch des österr.-ungar. Pilgerhauses, Jg. 1, S. 3.

${ }^{37}$ EISTERER, Erste allgemeine österreichische Pilgerfahrt, S. 145. 
Auch die Aufgaben und Pflichten des Generalkommissärs - eindeutig darauf abzielend, seine Kompetenzen begrenzt zu halten und Eigenmächtigkeiten zu verhindern - wurden in mehreren Paragraphen festgehalten. $\S 9$ hielt seine Rücksprache- und Informationspflicht fest - er hatte in allen wichtigeren Angelegenheiten das Kommissariat bzw. "Discretorium« zu Rate zu ziehen und von allen eingegangenen Geldbeträgen und eingelangten Schreiben in Kenntnis zu setzen. Weiters hatte der Generalkommissär über alle Ein- und Ausgänge ein Journal zu führen, das monatlich dem Diskretorium und jährlich dem Fürsterzbischof als Protektor vorzulegen war (§13). Jährlich mußte zudem ein detaillierter Rechnungsausweis im Druck bekanntgemacht werden: »Diesem Rechnungsausweise können auch eingegangene Nachrichten über den religiösen Zustand der Christen im Oriente, die zur Erbauung und Ermunterung der Gläubigen dienen, beygefüget werden.« $(\S 15)$ - Diese Bestimmung führte zum Erscheinungsbild der »Missions-Notizen aus dem heiligen Lande«, mit denen sich Generalkommissär Matzek an die Öffentlichkeit wandte. $\S 20$ enthielt die explizit angesprochene Unterordnung des Generalkommissärs unter den jeweiligen Fürsterzbischof: Dem Generalkommissär obliege die Leitung all dessen, was »die Erhaltung unserer heiligen Religion und die Beförderung des Seelenheiles der Menschen in dem heiligen Lande « fördern könne; er habe sein Amt »treu, gewissenhaft und eifrig zu verwalten « und im Wiener Kloster zu wohnen, von dem er auch erhalten wird. »Er ist für Alles verantwortlich, da die Discreten nur zu seinem Rathe und seiner Hülfe ihm beygegeben sind und ohne seinen Willen oder gegen denselben nichts beschließen können und dürfen. Dagegen ist er in Allem dem jeweiligen Fürst-Erzbischofe als Protector untergeordnet, den er von Allem in Kenntniß zu setzen und dessen Befehle er genau und willig zu vollziehen hat.« Im letzten Paragraphen, in $\S 21$, wurden die besonderen Verpflichtungen des Generalkommissärs, die sich zu einem großen Teil auf Korrespondenzen und andere Schreibarbeiten bezogen, festgehalten: 1. Führung der Korrespondenz mit allen Provinzialen des Franziskanerordens der Österreichischen Monarchie, wobei er sich auch, „so viel möglich ist, eine verläßliche Kenntniß der als Missionäre abgehen wollenden Individuen « erwerben sollte; 2. mußte er die Dankschreiben für eingesandte Beträge und die Rechnungsausweise an die Ordinariate schicken sowie deren etwaige Anfragen beantworten; 3. Führung der Korrespondenz mit dem Kustos in Jerusalem, mit dem »Commissarius terrae sanctae« in Konstantinopel, mit den Guardianen und Superioren der einzelnen Klöster im Orient; 4. hatte er diese auch mit den Missionären zu führen, wobei sich der Generalkommissär eine genaue Kenntnis des Zustandes der Klöster und der anderen religiösen Anstalten im Orient erwerben sollte; 5. alle eingegangenen Schreiben und das Konzept aller abgesendeten Schreiben hatte er sorgfältig aufzubewahren und in einem Protokoll mit kurzer Angabe des Inhaltes zu verzeichnen; als Punkt 6 wurde noch einmal die Rechnungsführung angesprochen: "Er führet genau 
und vollständig die Rechnung aller Empfänge und Ausgaben, verfasset die vollständige Rechnung und den Extract. Er bewahret alle Beylagen, um sich stets ausweisen zu können.«; 7. bis zum Betrag von 25 fl. C.M. konnte er selbst disponieren, höhere Beträge bedurften der Bewilligung des Protektors; 8. - nochmals die Aufgaben des Generalkommissärs hinsichtlich Information der Öffentlichkeit ansprechend - hatte er die Nachrichten über den religiösen Zustand der Christen im Orient zu sammeln und die in Druck zu legenden Notizen zu verfassen; 9. konnte er den Vizekommissär als Sekretär zu Schreibarbeiten heranziehen, der Generalkommissär selber aber war verantwortlich; 10. und letztens hatte sich der Generalkommissär »thätig und eifrig « in der Seelsorge in Wien zu verwenden.

Die Reihe der Männer, denen die Aufgabe, »Vertreter der geistigen und materiellen Interessen der Mission des Hl. Landes $\aleph^{38} \mathrm{zu}$ sein, übertragen wurde, setzt ein mit dem schon erwähnten P. Joseph Matzek, einem gebürtigen Ungarn (1843-1869); auf ihn folgten der Wiener P. Konrad Mühlhaupt (18691870) und der gebürtige Egerländer P. Sebastian Frötschner (1870-1881), der 1846 als Missionär nach Palästina gereist war und im Kloster St. Salvator in Jerusalem eine Buchdruckerei errichtete, wofür er von Kaiser Franz Joseph ausgezeichnet wurde. Von 1881 bis 1902 führte der Ungar P. Franz Sales Angeli das Wiener Generalkommissariat - wie Frötschner einst Missionär des Heiligen Landes, dort Leiter der genannten Buchdruckerei und Diskret der Kustodie. Angeli war der Begründer der "Armee des hl. Kreuzes« und vertrat das Generalkommissariat in der einschneidende Veränderungen nach sich ziehenden Auseinandersetzung mit Kardinal Gruscha. 1902 wurde er vom Ordensgeneral beauftragt, in Budapest ein eigenes Kommissariat für Ungarn und Kroatien einzurichten und auch zu leiten. Auf Angeli, der "gewissermaßen zum Markstein « des Wiener Generalkommissariats wurde, folgte der Tiroler P. Melchior Lechner (1902-1927), in dessen Amtszeit das Wirkungsfeld des Wiener Kommissariats durch die Errichtung einer ganzen Reihe von neuen Kommissariaten im Bereich des alten Österreich an Ausdehnung verlor. Er veränderte die von seinem Vorgänger gegründete Zeitschrift »Die Posaune des hl. Kreuzes« in »Der Kreuzfahrer« und begleitete zusammen mit Oberst Heinrich Himmel von Agisburg mehrere große Pilgerzüge ins Heilige Land ${ }^{39}$.

${ }^{38}$ Bedeutung der Kommissariate des Heiligen Landes, in: Österreichische Pilgerbriefe 1, S. 2.

${ }^{39} \mathrm{Vgl}$. zu den angeführten Generalkommissären WASNER, Geschichte des GeneralKommissariates von Wien, S. 18-22, Zitat S. 20; 500 Jahre Franziskaner der österreichischen Ordensprovinz, S. $128 \mathrm{f}$. 


\section{Die Verwaltung der Gelder}

»Das General-Commissariat trat gerade zu einer Zeit in's Leben, als die bloß auf Unterstützungen des christlichen Abendlandes angewiesenen Missionen des heil. Landes bei den häufigen Repressalien sich im kümmerlichsten Zustande befanden, da fast aus allen Ländern durch eine Reihe von Jahren die Sammlungsgelder ausblieben. $\ll^{40}$ - Der zentrale Faktor in der Arbeit des Generalkommissariats war von Anfang an die Aufbringung und Übersendung von möglichst großen finanziellen Mitteln, wobei es hinsichtlich der Almosenverwaltung und -verwendung als Pflicht der neuen Institution angesehen wurde, "mit aller Umsicht zu Werke zu gehen ${ }^{41}$.

In $\S 1$ der »Grundregeln und Vorschriften« wurde die Karwochenkollekte in der Monarchie zum Zweck der »Erhaltung und Unterstützung der christkatholischen Religion « in Palästina nochmals festgeschrieben. Die jährlich in allen Pfarren gesammelten Beträge sollten von den (erz)bischöflichen Konsistorien, geordnet nach den einzelnen Pfarren, an das Kommissariat eingesendet werden, das eine Empfangsbestätigung auszustellen hatte ( $(11)$. Die eingegangenen Geldbeträge wurden im Wiener Kloster in einer Kassa mit dreifacher Sperre aufbewahrt; die Schlüssel sollten sich in den Händen des Generalkommissärs, des Syndikus und des ältesten Assistenten befinden ( $\$ 12)$. In $\S 14$ schließlich ist nachzulesen, wofür die gesammelten Geldbeträge zu verwenden waren: als Reisegeld und zur Versorgung der Missionäre; zum Ankauf von Kirchengeräten, Utensilien, Büchern etc., die von den Klöstern im Orient benötigt wurden; zuletzt auch zu deren Unterstützung mit Bargeld.

\section{Österreichische Franziskaner in der Kustodie}

Das zweite große Wirkungsfeld, das dem Generalkommissariat zugeschrieben wurde, bestand in der Auffindung und Entsendung von österreichischen Franziskanern, die als Führer und Beichtväter für die Pilger aus der Monarchie fungieren sollten, in die Klöster der Kustodie. Denn: »Ueberall, wohin man in Palästina kommt, hört man den mächtigen Adlerflügelsschlag dieser segensreichen Institution der Wache des Heiligen Grabes und des Heiligen Landes. $\aleph^{42}$ Von der katholischen Kirchenorganisation her gesehen war Palästina bis 1847 Teil der eigentlich international angelegten Kustodie; 1847 setzte

${ }^{40}$ ZSCHOKKE, Das österreichische Pilgerhaus in Jerusalem, S. 137.

${ }^{41} \S \mathrm{X}$. Das Wirken des General-Commissariates, in: Missions-Notizen aus dem heiligen Lande 1 (1846) S. 29-35, hier S. 32.

${ }^{42}$ Friedrich ENDL, Bilder und Skizzen aus Egypten und Palästina von der Oesterreichischen Pilgerfahrt nach dem Heiligen Lande im Frühjahre 1894, Wien 1894, S. 79. 
Rom die Institution des lateinischen Patriarchats darüber, das wie die Kustodie unter französischem Protektorat stand.

So oblag dem ersten Generalkommissär - zurückgehend auf eine Anregung des Wiener Erzbischofs, wie oben ausgeführt - sogleich die Aufgabe, die seit sechs Jahrzehnten völlig abgeschnittene Verbindung der österreichischen Ordensprovinzen mit dem Heiligen Land wiederherzustellen und die österreichischen Franziskanerpatres zum Missionsdienst in jener Region aufzufordern. Laut Ordenssatzungen aus dem Jahr 1746 war schließlich jede Ordensprovinz berechtigt, zwei Patres für jeweils drei Jahre ${ }^{43}$ dorthin zu senden; dennoch waren zu Beginn der vierziger Jahre - bis auf einen einzigen »deutschen« Beichtvater, P. Felix Laasner aus Krakau - nur Italiener und Spanier in der Kustodie vertreten ${ }^{44}$.

Bereits in $\S 2$ der »Grundregeln und Vorschriften« wurde die Funktion des Generalkommissariats als reine Sammelstelle mit Hinblick auf die Betreuung der aus der Monarchie kommenden Pilger und auf eine Vertretung Österreichs in der Kustodie erweitert: »Da mit Unterstützungen an Gelde allein der Zweck nicht erreichet werden würde, sondern da es nothwendig ist, dafür zu sorgen, daß die in die heiligen Orte wallfahrtenden Christen dort fromme Priester finden, die ihrer Sprache kundig sind und für ihr Seelenheil wirken können, so sollen vier bis sechs Priester aus den Oesterreichischen Staaten, welche der deutschen und einer slavischen, oder der ungarischen, oder der italienischen, oder der französischen Sprache kundig sind, als Missionäre dahin gesendet und in Jerusalem, oder einem andern in Syrien oder Ägypten befindlichen Kloster unterhalten werden.« Nur Priester aus dem Franziskanerorden, der dort seit 1313 den Gottesdienst besorge, sollten als Missionäre in die Klöster in Jerusalem und in den anderen Orten Syriens und Ägyptens geschickt werden (§5). Die Missionäre sollten aus allen Provinzen der Österreichischen Monarchie gewählt werden, wobei sie dem Generalkommissär von ihren Provinzialen vorgeschlagen werden mußten. Als Auswahlkriterien galten Sprachkenntnisse, Gesundheit, Alter, Frömmigkeit und Engagement (»Eifer«). Der Generalkommissär hatte anschließend die Kandidaten dem Erzbischof in Vorschlag zu bringen, der dann letztlich bestimmte, wer - ausgestattet mit dem nötigen Reisegeld aus der Kommissariatskassa - wohin gesendet werden sollte $(\S 17)$. $\S 18$ legte den Zeitraum des Verbleibs der Missionäre fest:

Jeder Missionär hat durch sechs Jahre im Oriente zu verbleiben, sich dort der Seelsorge eifrig zu widmen, und, in so ferne es ihm möglich ist, die Sprache des Landes zu erlernen. Die Zeit des Aufenthaltes kann, wenn er es wünschet, verlängert werden, so wie er auch

${ }^{43}$ Nach den Ordensstatuten genügten drei Jahre zum Dienst des Heiligen Landes; seit 1841 wurden von der für das Missionswesen zuständigen Propaganda-Kongregation in Rom bei Visitanten jedoch sechs und bei Missionären sogar zwölf Jahre gefordert. $§ 18$ der "Grundregeln und Vorschriften« legte hingegen einen Zeitraum von sechs Jahren fest.

${ }^{44} \mathrm{Vgl}$. $\mathrm{X}$. Das Wirken des General-Commissariates, in: Missions-Notizen aus dem heiligen Lande 1, S. 29. 
früher, wenn Gründe vorhanden sind, zurückberufen werden kann. Nach seiner Rückkehr, wozu er das Reisegeld erhält, kehrt er in seine Provinz zurück, wenn er nicht zum Mitgliede des Commissariates in Wien gewählet wird [...].

Auch blieben die Missionäre nicht zwangsläufig während der ganzen Zeit ihrer Mission in Jerusalem, sondern konnten ebensogut in die anderen Klöster in Syrien, Ägypten und auf Zypern versetzt werden (§ 19).

Somit mußte zunächst Kontakt mit dem Kustos in Jerusalem aufgenommen und in den 15 österreichischen Ordensprovinzen ermittelt werden, wieviele geeignete Priester sich melden würden. Am 15. Juni 1844 wurde eine erste Anfrage nach Jerusalem gestellt, und am 1. März 1845 - als sich bereits fünf österreichische Ordenspriester gefunden hatten - eine zweite, auf die eine positive Antwort einlangte, wonach die Priester in die Kommunität der Kustodie aufgenommen würden, wenn sie mit Obedienzialen des Ordensgenerals versehen ankommen würden. Das Generalkommissariat wollte den Missionskandidaten noch eine Vorbereitungszeit zum Studium der italienischen bzw. arabischen und auch türkischen Sprache ermöglichen. In seiner Sitzung vom 19. Dezember wurde bestimmt, nunmehr die Meinungen der entsprechenden Ordinariate über die fünf Kandidaten einzuholen und anschließend zu ihrer Präsentierung zu schreiten, woraufhin bereits am 7. März 1846 für zwei Kandidaten vom Ordensgeneral die Absendungsurkunden ausgestellt wurden; für die anderen wollte die Propaganda zunächst eine Übereinstimmung mit ihren Dekreten erreicht wissen.

Diesem zu Folge hat man am 8. April dem Ordensvorstande die Erklärung eingesendet, daß wohl Pater Peter Friedland sich zum Missionsdienste auf 12 Jahre und zur vollständigen Erlernung der arabischen Sprache im heil. Lande herbeigelassen habe; da jedoch der Hauptzweck der Sendung aus den österreichischen Ordensprovinzen der ist, daß die in die heil. Orte wallfahrtenden hierländischen Christen sprachkundige Beichtväter an verschiedenen heil. Stellen träfen und dieser Zweck durch die sofortige Bestimmung aller 5 Individuen in ein arabisches Collegium minder erreicht würde, bat man, die 4 Missionskandidaten, Barnabas Rufinatscha, Sebastian Frötschner, Eduard von der Strassen und Anselm Janotyik gemäß dem früheren Vorschlag einstweilen auf 6 Jahre als Beichtväter der deutschen, slavischen und ungarischen Pilgrime bestimmen zu wollen, bis die Erfahrung zeigt, ob sie indeß die Volkssprache im heil. Lande sich aneignen und sodann sich verpflichten können, das Clima andere 6 Jahre hindurch zu ertragen.

Fürsterzbischof Milde lud mittlerweile den Görzer Professor Johann Mosetizh gegen einen Unkostenbeitrag von 2000 fl. C.M. ein, »nach Syrien und Egypten die Reise zu unternehmen, die Missionsbedürfnisse zu erheben und die Lage der Dinge zum Behufe der zweckmäßigen Wirksamkeit des Commissariates nach Thunlichkeit kennen zu lernen«; Ende Januar 1846 reichte Mosetizh daraufhin einen ausführlichen Bericht über seine Beobachtungen ein ${ }^{45}$. 
Am 29. März 1849 trafen zwei weitere Franziskaner aus der Monarchie in Jerusalem ein: P. Mathias Arnold und P. Wolfgang Rauchbart ${ }^{46}$.

1847, als die ersten fünf österreichischen Franziskaner bereits in der Kustodie eingetroffen waren, befanden sich dort 110 Priester und 77 Laienbrüder, insgesamt also 187 Franziskaner, wworunter der Nation nach 1 Pole, 1 Ungar, 1 Lombarder, 1 Küstenländer, 2 Deutsche, 2 Böhmen, 4 Portugeser [sic!], 51 Spanier, die Uebrigen Italiener sind $\aleph^{47}$.

\section{Exkurs: Konflikt mit dem Patriarchat}

Die jahrhundertelange Monopolstellung des Franziskanerordens wurde um die Mitte des 19. Jahrhunderts aufgebrochen, woraus grundlegende innerkatholische Konflikte resultierten. Nicht nur war die Veränderung in der Hierarchie eine für die Franziskaner mit allen (auch finanziellen) Konsequenzen höchst unangenehme Entwicklung, sondern mit der Wiedererrichtung des lateinischen Patriarchats in Jerusalem 1847 war der Franziskanerorden mit einem Schlag auch nicht mehr der alleinige Faktor der katholischen Mission im Heiligen Land - der erste Schritt zu einem immer größer werdenden kirchlichen Spektrum in der zweiten Hälfte des 19. Jahrhunderts war getan ${ }^{48}$. Die österreichischen Franziskaner beklagten sich gegenüber ihrem Generalkommissär auf das heftigste über die neu geschaffene Situation.

Über Jahre ging es nunmehr darum, das rechte Verhältnis zwischen Patriarchat und Kustodie zu finden. Das Patriarchat war »von finanziellen Beiträgen der Kustodie abhängig, mußte 14 seiner Gemeinden von franziskanischen Mönchspriestern versorgen lassen und stand mit seinen 80 Weltpriestern der Kustodie mit ihren 330 Franziskanern in einer Minoritätssituation gegenüber. [...] Das Patriarchat half sich, indem es auch andere Kongregationen ins Hei-

${ }^{46}$ Vgl. § XVI. Reisebericht des P. Mathias Amold und P. Wolfgang Rauchbart, in: Missions-Notizen aus dem heiligen Lande 3 (1849) S. 68-73, hier S. 68. P. Anselm, noch 1847 zum Präsidenten des Franziskanerkonvents in der Grabeskirche gewählt, hatte Jerusalem aus gesundheitlichen Gründen bald darauf wieder verlassen müssen.

${ }^{47} \S$ V. Dießjähriger Personalstand der h. Custodie, in: Missions-Notizen aus dem heiligen Lande 2 (1847) S. 18. Hieraus sind auch Angaben zur Person - unter anderem zu Geburtsort und Alter - der ersten aus der Monarchie entsandten Franziskaner zu entnehmen: P. Barnabas, geb. in Taufers (Tirol), 46 Jahre alt; P. Sebastian, geb. in Eger (Böhmen), 39 Jahre alt; P. Eduard, geb. in Salurn (Tirol), 38 Jahre alt; P. Anselm, geb. in Rosenberg (Ungarn), 35 Jahre alt; P. Peter, geb. in Böhmisch-Leipa, 36 Jahre alt.

${ }^{48}$ Die immer größer werdende Differenzierung unter den an der Mission im Heiligen Land beteiligten Faktoren führte in späteren Jahren auch zu Kritik an der als veraltet und überholt angesehenen Einrichtung des Generalkommissariats. Die Forderung nach einer zentralen Missionskassa, aus der das Generalkommissariat jährlich einen entsprechenden Betrag erhalten sollte, wurde in Österreich-Ungarn aber wie der von vielen Seiten immer lauter werdende Plan der Schaffung eines allgemeinen österreichischen Missionsvereins nicht verwirklicht. 
lige Land zog und die Gründung der einheimischen Kongregation der 'Schwestern des allerheiligsten Rosenkranzes begünstigte. Damit wurde den Franziskanern die Stellung des alleinprivilegierten Ordens genommen." Rom grenzte zwar mit dem Dekret Licet vom 9. September 1851 die Zuständigkeiten der beiden lateinischen Instanzen gegeneinander ab, aber letztlich waren erst 1923 alle kirchenrechtlichen Fragen hinreichend geklärt ${ }^{49}$. In diesem Streit der ersten Jahre stützten sich die Franziskaner auf österreichischen Einfluß, der erste Patriarch Giuseppe Valerga hingegen auf die Schutzmacht Frankreich.

Im Februar 1854 informierte das Ministerium des Äußern den Nachfolger Mildes als Wiener Fürsterzbischof, Joseph Othmar von Rauscher, darüber, daß in Rom ein Kompromiß mit dem Ordensgeneral der Franziskaner »betreffs der Gebarung mit den Sammelgeldern der Terra Santa" gefunden worden sei, zu dessen Bestimmungen beizutreten Österreich eingeladen worden sei. Der Kompromiß würde sich aus folgenden Bestimmungen zusammensetzen: a. Für die Terra Santa soll nur eine Kassa bestehen, in welche alle Sammelgelder fließen sollen. b. Die Verwaltung der Kassa obliegt sechs Definitoren der Franziskaner-Kustodie unter dem Vorsitz des Patriarchen von Jerusalem, der wie jeder der Definitoren nur eine Stimme hat. c. Die Kassa-Verwaltung entwirft jährlich einen Budgetvoranschlag, der der Propaganda in Rom zur Genehmigung vorgelegt wird. Ebenso ist der Propaganda ein Jahresausweis einzusenden. d. Der Patriarch erhält aus den jährlichen Einnahmen der Kassa ein Fünftel (und nicht mehr). - Auf Anregung von Kardinalstaatssekretär Antonelli sollten auf dieser Grundlage Besprechungen mit den »katholischen Hauptmächten « Österreich, Frankreich und Spanien eingeleitet werden, wobei durchaus noch Verhandlungsspielraum bestehe, nur an den Prinzipien der Einheit der Kassa und des Präsidiums des Patriarchen müsse festgehalten werden. Das Ministerium des Äußern bat den Fürsterzbischof um seine Meinung darüber, inwieweit sich der kaiserliche Geschäftsträger in Rom an diesen Besprechungen beteiligen solle ${ }^{50}$.

Rauscher äußerte in seiner Antwort an den Minister des Äußern, Grafen Buol, daß Österreich seiner Meinung nach - wie auch Spanien und Frankreich dem gefundenen Kompromiß beitreten sollte, um die in Rom gegen die Monarchie vorherrschende negative Stimmung nicht noch weiter zu vertiefen. Mit dem Hinweis, daß für die österreichischen Projekte - die in Jerusalem gegründete Buchdruckerei, die Errichtung des Pilgerhauses und die Bedürfnisse der österreichischen, in Palästina wirkenden Franziskaner - gesorgt werden müsse, meinte Rauscher: »Ich glaube daher, daß man dem Compromiß beitreten und bei Seiner Majestät die allerhöchste Genehmigung nachsuchen sollte, um das bestehende General-Commissariat in diesem Sinne umzu[ge]stalten.« Das für

${ }^{49}$ Friedrich HEYER, Kirchengeschichte des Heiligen Landes, Stuttgart, Berlin, Köln, Mainz 1984, S. 190.

${ }^{50}$ Ministerium des Äußern an Rauscher, Wien, 1854 Februar 18, in: HHStA, AR, F 53, K 5. 
das Generalkommissariat verfügbare Kapital habe Ende Februar 1854 $128000 \mathrm{fl}$. C.M. betragen, wovon als größter Posten die seit langem im Raum stehende Realisierung des Pilgerhauses zu bestreiten sei. Im Anschluß an seinen Vorgänger regte Rauscher an, daß das im Zuge der Aufhebung des Generalkommissariats dem ungarischen Religionsfonds zugewiesene Vermögen, dessen Jahresertrag zur Heranbildung der für die bosnischen Missionen bestimmten Franziskaner verwendet wurde, dem wiederhergestellten Generalkommissariat ebenso wie die von Kaiser Rudolf II., Erzherzog Matthias und Erzherzog Maximilian für das Heilige Land gemachten Stiftungen zurückgegeben werden (die drei erwähnten Stiftungen würden jährlich 1200 fl. C.M. abwerfen).

Auf diese Weise wäre es möglich, für die Buchdruckerei, das Pilgerhaus und die Verpflegung der österreichischen Franziskaner aus dem Stammvermögen des Generalcommissariates zu sorgen, ohne den Ertrag der jährlichen Sammlungen in Anspruch zu nehmen; ja es würde sich sogar ein beträchtlicher Überschuß herausstellen. Über die Verwendung desselben Etwas zu sagen, ist natürlich viel zu früh; ich deute nur vorläufig an, daß viele Schwierigkeiten wegfallen würden, wenn von Seite Österreichs eben so wie von Seite Frankreichs dem jeweiligen Patriarchen von Jerusalem ein jährlicher Beitrag zu seinem Lebensunterhalte gegeben würde.

Der Patriarch sei in Palästina schließlich »der Träger der rechtmässigen Kirchengewalt, und ohne seine wohlwollende Mitwirkung wird das katholische deutsche [!] Element zu Jerusalem den ihm gebührenden Platz nicht einnehmen $\aleph^{51}$.

So wurden im Laufe der Jahre Annäherungen zwischen den beiden Positionen gefunden, die Wogen glätteten sich, und die skizzierte scharfe Frontenstellung zwischen Kustodie und Patriarchat wurde allmählich aufgeweicht. Unvermutet hatte die von franziskanischer Seite zunächst so heftig kritisierte Veränderung in der kirchlichen Struktur Palästinas für Österreich letztlich aber auch den Anstoß für die Realisierung des Projektes eines eigenen nationalen Hospizes mit sich gebracht.

\section{Das Protektorat des Wiener Erzbischofs}

Hatte doch Erzbischof Milde die "Grundregeln und Vorschriften« für das Generalkommissariat ausgearbeitet, so finden sich darin deutliche Bestimmungen hinsichtlich der Unterordnung des Generalkommissärs unter den jeweiligen Wiener Erzbischof (vgl. § 20). Vor allem die Kontrolle über die Finanzen wollte der Erzbischof fest in seinen und den Händen seiner Nachfolger verankert wissen.

${ }^{51}$ Rauscher an Buol-Schauenstein, Wien, 1854 März 15, ibid. 
In $\S 4$ wurde das Protektorat festgeschrieben: »Der jeweilige FürstErzbischof von Wien hat als Protector die Aufsicht und Leitung über das Commissariat zu führen und im Verhinderungsfalle einen Stellvertreter zu bestimmen. Im Falle der Erledigung des Erzbisthumes soll der Generalvicar der Wiener-Erzdiöcese einstweilen die Geschäfte führen. « $\S 10$ hielt fest, daß folgende Beschlüsse des Kommissariats immer der Genehmigung des Protektors bedurften: die Absendung oder Zurückrufung eines Missionärs; die Bestimmung und Übersendung von Geldbeträgen für das Heilige Land; der Einkauf und die Übersendung von Kirchengeräten bzw. anderen Utensilien; die Bekanntmachung des Rechnungsabschlusses und der Missionsnachrichten; die einstweilige »Elocirung" - gemeint ist hier wohl »Kapitalisierung" - der eingegangenen Sammlungsgelder, „da ein Theil für unvorgesehene Fälle aufbewahret werden soll«. Das vom Generalkommissär zu führende Journal über Einnahmen und Ausgaben mußte dem Protektor jährlich mit allen Beilagen vorgelegt werden $(\S 13)$, der wiederum seinerseits dem Kaiser jährlich einen vollständigen Rechnungsausweis zu unterbreiten hatte (§16). Der Generalkommissär hatte dem Erzbischof zudem die Missionskandidaten in Vorschlag zu bringen $(\S 17)$.

\section{Römischer Widerstand}

Gleich nach seiner Wiedergeburt sahen sich das Wiener Generalkommissariat und mit ihm die Spitzen des österreichischen Staates mit einem beträchtlichen römischen Widerstandspotential konfrontiert. Die Beanstandungen, die in den Zentralstellen in Rom - neben der Propaganda protestierte auch der Ordensgeneral der Franziskaner wegen der ins Ordensleben gemachten Eingriffe - laut wurden, richteten sich gegen Bestimmungen in den neuen "Grundregeln und Vorschriften«, worüber Metternich dem Kaiser, auf dessen Entschließung die „Grundregeln und Vorschriften $«$ ja beruhten, Vortrag erstattete ${ }^{52}$. Der päpstliche Nuntius, Ludovico Altieri, habe verschiedene Beschwerden mitgeteilt, die die Propaganda-Kongregation

unerwartet gegen die unter dem 16. Dezember 1843 publizirten Grundregeln und Vorschriften für das hier errichtete General-Kommissariat der heiligen Länder zu erheben findet. Diese Beschwerden betreffen hauptsächlich die vermeinte Einmischung der weltlichen Gewalt in die Verfassung eines geistlichen Ordens, nämlich der Franziskaner, und in das Missionswesen, die dem hiesigen Erzbischofe eingeräumte Befugniß, Missionäre in die heiligen Lande zu senden, da doch dieses Recht allein der heiligen Propaganda zusteht, und überdieß für die Bedürfnisse der nach den heiligen Orten wallenden Gläubigen durch päpstliche Anordnungen Vorsorge getroffen ist, endlich überhaupt die Erlassung einer Anordnung, wozu die Genehmigung des Kirchen-Oberhauptes erforderlich gewesen wäre.

${ }^{52}$ Metternich an Kaiser Ferdinand, Wien, 1844 September 27 (resolviert am 15. März 1845), ibid. 
Die Propaganda verkenne dabei jedoch nicht das prinzipiell Lobenswerte am neu eingerichteten Generalkommissariat, und der Nuntius habe dessen Genehmigung durch den Heiligen Stuhl mit Sicherheit in Aussicht gestellt, "sobald die erwähnten Vorschriften mit den erforderlichen Modifikationen und Abänderungen der Sanktion Sr. Heiligkeit unterzogen würden«. Die in den »Grundregeln und Vorschriften« vorzunehmenden nötigen Änderungen seien zunächst mit der Vereinigten Hofkanzlei und dem Erzbischof von Wien zu diskutieren. - Hier zeigte Metternich noch Entgegenkommen gegenüber Rom und Bereitschaft zu Änderungen, die aber letztlich nicht zum Tragen kamen.

Wie aus der Resolution des Kaisers zu entnehmen ist, äußerte sich der Fürsterzbischof von Wien daraufhin in dem Sinn, »daß den gegen dieses Commissariat erhobenen Anständen hauptsächlich zwey Mißverständnisse zum [!] Grunde liegen«. Zum einen, »als ob das früher bestandene Commissariat des Franziskaner Ordens wieder hergestellt worden wäre«, und zum anderen, »als ob dem Erzbischofe von Wien durch diese Verfügung bezüglich der Bestellung von Missionären nach dem heiligen Lande Eingriffe in die Jurisdiktion der Ordensvorstände und der Congregation de propaganda fide eingeräumt worden wären, da doch in derselben von der Annahme und Jurisdiktionirung dieser Missionäre, welche sie sich allzeit bey den betreffenden Obern zu erwirken haben, keine Rede ist $«$. Metternich solle den Nuntius zur Beruhigung der Propaganda auf diese Mißverständnisse aufmerksam machen.

Letztlich rückte Wien nicht von seinen Positionen ab: $\gg D a$ jedoch der Kaiser erklärte, das Commissariat werde nur unter diesen Bedingungen in Österreich zugelassen, so gab sowohl Rom, wie auch der General der Franciscaner nach. ${ }^{53}$

\section{Der Kaiser und das Generalkommissariat - zu einem Aspekt habsburgischer Frömmigkeit}

Das österreichische Herrscherhaus mit seinen den Anspruchstitel »König von Jerusalem « führenden Kaisern stellte sich seit jeher zum Ausdruck der ideellen Präsenz des Erzhauses in die Reihe der größten Wohltäter der Kustodie des Heiligen Landes und der Heiligen Stätten ${ }^{54}$.

${ }^{53}$ Zur Geschichte des österreichisch-ungarischen Hospizes in Jerusalem, in: Protokoll der bischöflichen Versammlung in Wien vom 23. bis zum 27. November 1897, S. 121f., hier S. 121, in: DAW, BIKO, Karton 8, 1887-1900.

${ }^{54}$ Vgl. Günther RamHaRdTER, Propaganda und Außenpolitik, in: Adam WandruszKa, Peter URBANITSCH (Hg.), Die Habsburgermonarchie 1848-1918, Bd. 6/1: Die Habsburgermonarchie im System der internationalen Beziehungen, Wien 1989, S. 496-536, hier S. 514-516; Arthur BREYCHA-VAUTHIER, Österreich in der Levante. Geschichte und Geschichten einer alten Freundschaft, Wien, München 1972, 54-58. 
Im Bericht von Angelus Stummer über den Tiroler Papst- und Kaiserjubiläumspilgerzug im Jahr 1898 findet sich ein Kapitel »Unser Kaiserhaus und das Heilige Land«, in dem das Engagement und die Zuwendungen der habsburgischen Kaiser für das Heilige Land von Rudolf II. und Ferdinand II. über Leopold I. und Karl VI. bis zu Maria Theresia und Ferdinand I. dargestellt wird, gipfelnd in der Gestalt Franz Josephs I., der Jerusalem bekanntlich 1869 als erster christlicher Kaiser seit 600 Jahren besuchte ${ }^{55}$ : Bereits Rudolf II. habe 1587 große Summen ins Heilige Land gesandt. Kaiser Ferdinand II., der Errichter eines Generalkommissariates des Heiligen Landes in Wien, habe eigenhändig an den Sultan geschrieben, um die für die Franziskaner verlorengegangenen Heiligen Stätten wieder zurückzugewinnen. Kaiser Leopold I. erhielt das unterdessen wieder verlorene Heilige Grab, unterstützt von den Königen Frankreichs und Polens sowie von der Republik Venedig, für die Franziskaner zurück (1664); in den Frieden von Karlowitz (1699) ließ er einen das Heilige Land betreffenden Artikel einfügen, worin dem kaiserlichen Gesandten das Recht zugestanden wurde, bei der Pforte etwaige Beschwerden vorzubringen. Kaiser Karl VI. wiederum habe dem Grab des Erlösers eine goldene Lampe geopfert. Außerdem habe er es beim Friedensschluß von Passarowitz (1718) zustande gebracht, da $B$ nach einer allgemeinen Beratung der europäischen Fürsten die Franziskaner so unterstützt wurden, daß die dem Einsturz nahe Kuppel der Heiligen Grabeskirche wieder hergestellt werden konnte. Auch Franz I. und Maria Theresia hätten viel zugunsten des Heiligen Landes getan: Nicht nur sei die Lampe Karls VI. renoviert und kostbarer verziert worden, sondern auch ein von Maria Theresia selbst angefertigter Ornat und ein Thronhimmel aus Goldstoff, der in der Mitte das österreichische Wappen zeigt, seien Geschenke dieses Herrscherpaares. Ferdinand I. schließlich komme mit der Wiedereinführung der Karwochenkollekte und der Wiedererrichtung des Wiener Generalkommissariats das Verdienst zu, »die fast 60 Jahre unterlassene Fürsorge wieder aufgenommen « zu haben.

In den von ihm im November 1843 sanktionierten »Grundregeln und Vorschriften « war festgehalten, daß der Generalkommissär stets der Bestätigung durch den Kaiser bedurfte $(\S 6)$ und diesem jährlich vom Protektor ein vollständiger Rechnungsausweis vorzulegen war (\$16).

Eine herausragende Position kommt im Zusammenhang mit der habsburgischen Unterstützung für die Kustodie Kaiser Franz Joseph I. zu. Franz Joseph, der sich während seines Aufenthalts in Jerusalem nach allen Seiten sehr freigiebig zeigte, hatte gerade auch für die Anliegen der Franziskaner im Heiligen

${ }^{5 s}$ Vgl. Angelus STUMMER, Tirol an des Erlösers Grab. Pilgrims Reise-Erzählungen vom Tirol-Vorarlberger Papst- und Kaiserjubiläums-Pilgerzuge (Diöcese Brixen). 5. bis 28. October 1898, Brixen 1899, S. 164-171, hier S. 168f., Zitat S. 169. Diese Aufzählung habsburgischen Engagements und habsburgischer Wohltätigkeit für die Heiligen Stätten ist nur als »Spitze eines Eisbergs« zu sehen und durch viele Namen ergänzbar. 
Land ein besonders offenes Ohr. So verhalf er ihnen durch Intervention beim Sultan (und eine Spende von 3000 Francs) zu einer besseren Unterbringung in der Grabeskirche und übernahm die finanzielle Hauptlast der - sich über Jahre hinziehenden - Erneuerung der beiden großen Franziskanerkirchen in Palästina, St. Salvator in Jerusalem und St. Katharina in Bethlehem ${ }^{56}$. Nicht ohne Grund zeigen die 1890 anläßlich des zwanzigjährigen Jubiläums seiner Pilgerfahrt ins Heilige Land vom Kaiser gestifteten Glasfenster in der Kapelle des österreichischen Hospizes in Jerusalem den Stifter kniend vor seinen Namenspatronen, dem Hl. Franziskus, Ordensgründer der Franziskaner, und dem HI. Joseph ${ }^{57}$.

\section{Zur Wirksamkeit des Wiener Generalkommissariats}

Die Einrichtung von Kommissariaten des Heiligen Landes war nun keine auf die Habsburgermonarchie beschränkte, sondern eine internationale - vornehmlich auf den Alten und Neuen Kontinent ausgreifende - Entwicklung. 1868 waren Kommissäre für das Heilige Land tätig in: Italien, Spanien, Frankreich, Österreich, Belgien (dort auch für die Niederlande und Preußen zuständig), auf den Philippinischen Inseln, in Brasilien, in Chile, Peru und Mexiko ${ }^{58} .1882$ war als elfter Kommissär mittlerweile derjenige für die Konföderierten Staaten von Amerika hinzugekommen ${ }^{59}$. Im $»$ Brevis conspectus « der Franziskanerkustodie aus dem Jahr 1909 scheinen hingegen bereits 42 Kommissariate und zwei Vizekommissariate - eines in Messina auf Sizilien und eines in Agram (Zagreb) - auf. Unter den Kommissariaten finden sich drei auf dem Gebiet der

${ }^{56}$ Vgl. Bernhard A. BÖHLER, Kaiser Franz Joseph im Heiligen Land. Ein Beitrag zur Erforschung seiner Orientreise im Jahr 1869, in: DERS. (Hg.), Mit Szepter und Pilgerstab. Österreichische Präsenz im Heiligen Land seit den Tagen Kaiser Franz Josephs, Katalogbuch Wien 2000, S. 161-202, hier S. 193-195. Abgesehen von den Spenden für die beiden großen Franziskanerkirchen (je 60000 Francs aus seiner Privatkasse), widmete der österreichische Kaiser den höchsten Geldbetrag bemerkenswerterweise der 1869 noch unvollendeten Patriarchatskirche als Beitrag zu deren künstlerischen Ausstattung.

${ }^{57} \mathrm{Vgl}$. Dagmar REDL, Das österreichische Hospiz in Jerusalem. Ein >Kunstexport ‘ des Historismus, und Bernhard A. BöHLER, Franciscus Iosephus Austriae Imperator ante portas Hierosolymae. Ein Mosaik in der Kapelle des österreichischen Hospizes zur Heiligen Familie in Jerusalem als Denkmal für den `König von Jerusalemı, in: BÖHLER (Hg.), Mit Szepter und Pilgerstab, S. 89-127, hier S. 120, bzw. S. 129-139, hier S. 129f.

${ }^{58} \mathrm{Vgl}$. Prospectus locorum et religiosorum Ordinis Minorum S. Francisci Custodiae Terrae Sanctae, Hierosolymis 1868 , S. 79. Die Kustodie umfaßte insgesamt $36 »$ domiciliae« (Konvente und Hospize).

${ }^{59}$ Prospectus Almae Seraphicae Custodiae Terrae Sanctae septimo vertente centenario ab ortu Seraphici Patriarchae divi Francisci Assisiatis cura Rmi. Patris Guidi a Cortona totius Terrae Sanctae Custodis editus a. D. MDCCCLXXXIl, Hierosolymis [1882], S. 69. 
österreichisch-ungarischen Monarchie gelegene, und zwar neben Wien die Standorte Budapest und Lemberg (Lwów, Lviv) ${ }^{60}$. Vor Ausbruch des Ersten Weltkrieges belief sich die Zahl der Kommissariate schließlich auf 44; sie beschäftigten 84 Patres und 150 Brüder $^{61}$.

Das Wiener Generalkommissariat leistete - wie im 19. Jahrhundert gefordert - Missionsarbeit nicht nur nach außen, sondern durch Informationsveranstaltungen, Publikationen, Veranstaltung von Pilgerfahrten und Vereinsbildung auch nach innen. Von Wien aus wurde so eine Informationsoffensive auf die mobilisierbaren Bevölkerungsteile der Habsburgermonarchie losgelassen.

Diesem Zweck dienten zuallererst die von den jeweiligen Wiener Generalkommissären herausgegebenen Missionszeitschriften ${ }^{62}$ : von 1846 bis 1887 die »Missions-Notizen aus dem heiligen Lande«, gefolgt von der nur 1888/89 erscheinenden Publikation »Die Mission im hl. Lande«. Noch 1889 erschien das erste Heft von »Die Posaune des hl. Kreuzes«, die bis 1901 veröffentlicht wurde. Generalkommissär P. Lechner gab mit Beginn seiner Amtszeit (1902) schließlich eine Zeitschrift mit dem programmatischen Titel »Der Kreuzfahrer $\ll$ heraus ${ }^{63}$. Die genannten Publikationsorgane dienten nicht nur der Information der interessierten Öffentlichkeit und der Erreichung einer möglichst großen Spendenkonzentration, sondern gemäß den »Grundregeln und Vor-

${ }^{60} \mathrm{Vgl}$. Brevis conspectus almae Custodiae et Missionis Terrae Sanctae quem R.mus P. Robertus Razzóli totius Terrae Sanctae Custos in generalibus comitiis ad S. Mariae Angelorum anno Domini MCMIX offert, Hierosolymis [1909]. Die meisten Kommissariate befanden sich in Südamerika bzw. Europa, drei aber auch in Nordamerika sowie eines in Australien.

${ }^{61} \mathrm{Vgl}$. ARENS, Handbuch der katholischen Missionen, S. 283f. In der Wiener Zeitschrift Der Kreuzfahrer ist nachzulesen, daß es 191443 Kommissariate gab, darunter als ältestes dasjenige von Neapel. Vgl. Die Kommissariate des Heiligen Landes, in: Der Kreuzfahrer. Monats-Zeitschrift der Wächter des heil. Grabes in Jerusalem und zugleich des PalästinaPilgervereines der Diözese Brixen 13 (November 1914) S. 25f. Im Laufe des 19. Jahrhunderts büßten die Generalkommissariate in Madrid, Rom, Wien und Paris ihre übergeordnete Stellung ein und wurden den übrigen Kommissariaten gleichgestellt, die nicht mehr für jede Provinz, sondern für ein mehr oder minder großes Gebiet errichtet wurden. Vgl. HOLZAPFEL, Handbuch der Geschichte des Franziskanerordens, S. 552.

${ }^{62}$ Die Franziskaner reihten sich mit ihren Publikationsorganen in die Flut an Veröffentlichungen über Missionen im allgemeinen und die Mission in Palästina im speziellen ein, die in der europäischen Bevölkerung des 19. Jhs. auf große Resonanz stieß. Diese Form der "Volksbelehrung " und "Volkserziehung « kulminierte in vor allem wohl weite ländliche Leserkreise erreichenden Publikationen wie: Das Heilige Land. Wie's dort ausschaut und was die Leute machen. Treuherzig und volkstümlich erzählt vom Jerusalemer-Franzl, Graz 1907. Beim Jerusalemer-Franzl handelte es sich um den steirischen Franziskanerpater Franz Schmid; auch er hatte seine Reiseerzählungen - wie vielfach der Fall - zunächst in einem Periodikum veröffentlicht.

${ }^{63}$ Ebenso publizierte er 1902 einen Pilgerreisebericht: Melchior LECHNER, Die Tiroler Pilger im heil'gen Land, Als das Jahrhundert im Beginne stand. Gedenkbuch an die beiden Tiroler Pilgerzüge nach Jerusalem im September und October 1901, Innsbruck 1902. 
schriften« insbesondere auch der Veröffentlichung des jährlichen Rechnungsausweises ${ }^{64}$.

Im Rahmen des katholischen Vereinswesens erlebten die Missionsvereine im Europa des 19. Jahrhunderts ihre Blütezeit. In Wien wurde 1891 von Generalkommissär Angeli ein solcher Verein mit der Zielrichtung Heiliges Land eingerichtet: die »Armee des hl. Kreuzes«. Als Hauptgrund für diese Gründung ist der Umstand anzusehen, daß die Almosen der Karwochenkollekte für die Bedürfnisse der Mission des Heiligen Landes nicht mehr ausreichten. Die Mitglieder des neuen Vereins, auch unter den Namen "Kreuzfahrerverein « oder das "Gute Werk vom Hl. Lande» bekannt, verpflichteten sich, jährlich nach ihrem Vermögen einen Betrag für das Heilige Land zu entrichten; die Kommissäre des Heiligen Landes waren stets auch die Direktoren dieses Ver$e^{e i n s}{ }^{65}$. Ein Förderer bzw. eine Förderin mußte wenigstens zwölf Vereinsmitglieder gewinnen. Allen Mitgliedern wurden viele geistliche Vorteile versprochen (neben der Gewinnung von Ablässen sollten sie vor allem Anteil haben an den in der Kustodie gelesenen Messen). »Die Waffen dieser geistlichen Kreuzfahrer sind: Frommes Gebet und milde Gaben. ${ }^{66}$

Starke Impulse für die Tätigkeit des Generalkommissariats gingen von der bereits angesprochenen, 1845 von Johann Mosetizh unternommenen Reise aus. Nicht nur aus Rom wurde in den ersten Jahren des Bestandes des Wiener Generalkommissariats Widerstand laut, sondern auch innerhalb des Franziskanerordens kam es mit dessen Wiedererrichtung zu Problemen: Innerhalb der ersten drei Jahre erbrachten die Sammelgelder für das Heilige Land an die $100000 \mathrm{fl}$., die aber in Wien brachlagen, "weil der Reverendissimus zu Jerusalem, von einer falschen Ansicht über den Charakter des diese Angelegenheit in Wien behandelnden Commissariates irregeleitet, mit diesem Commissariate jeden Verkehr verweigert [...].« Fürsterzbischof Milde wandte sich daher an Kaiser Ferdinand, um eine Entschließung zu erhalten, wie es künftig mit dem Kommissariat zu halten sein werde ${ }^{67}$.

Als Sofortmaßnahme schickte Milde Johann Mosetizh, Professor für Altes Testament und orientalische Sprachen am erzbischöflichen Seminar in Görz ${ }^{68}$, auf Reisen. 1846 übermittelte Milde Staatskanzler Metternich eine Abschrift des von Mosetizh eingereichten Berichtes süber den Zustand der Kirchen und

${ }^{64} \mathrm{Vgl}$. dazu die $\S \S 15$ und $21 / 8$.

${ }^{65} \mathrm{Vgl}$. Bedeutung der Kommissariate des Heiligen Landes, in: Österreichische Pilgerbriefe 1, S. 2.

${ }^{66}$ Die Armee des heiligen Kreuzes (auch Kreuzarmee oder Kreuzfahrer-Verein genannt), ibid. S. 11.

${ }^{67}$ Kaiser Ferdinand an Metternich, Schönbrunn, 1845 Juni 3, in: HHStA, AR, F 53, K 5.

${ }^{68}$ Siehe zu Mosetizh und den Ergebnissen seiner Reise auch ELIAV, HAIDER (Hg.), Österreich und das Heilige Land, S. 45f., 101-103. 
Klöster in Syrien und Egypten ${ }^{69}$. Mosetizh schilderte darin die katholische Gemeinde von Jerusalem - inklusive der 60 europäischen Klosterbewohner als 900 bis 1000 Seelen umfassend. Der Professor zeichnete ein - vor allem auch im Vergleich mit den Griechisch-Orthodoxen und Armeniern - düsteres Bild der räumlichen und finanziellen Situation der Franziskaner gerade auch in Jerusalem. »Die 22 Convente des heiligen Landes sind von 170 bis 180 Religiosen aus Europa bewohnet, die theils der Spanischen, größtentheils aber der Italienischen Nation angehören. In einigen Conventen leben bloß Spanier, in anderen nur Italiener; in Jerusalem, Nazareth und Bethlehem aber leben sie gemeinschaftlich.« In diesem Bericht tauchte die Idee der Gründung einer Buchdruckerei zum ersten Mal auf: Zur Verbesserung des Schulwesens sei eine Aufstockung der dürftigen Bestände der Bibliotheken in den Missionsstationen, auch die Herstellung von Übersetzungen ins Arabische vonnöten, schrieb Mosetizh.

Um aber dieses thun zu können, müßte die Mission des h. Landes in irgend einem Orte Palästinas, z.B. in Jerusalem, dem Hauptsitze der Missionen, eine kleine, mit Arabischen und Italienischen Lettern hinlänglich versehene Buchdruckerey besitzen, um die besseren zur Belehrung, Erziehung und Erbauung dienenden Schriften zu vermehren, unter der heranwachsenden Jugend zu vertheilen, und sie so gegen die Verführung der Nordamerikanischen Presbyterianer und Englisch-protestantischen Missionäre zu verwahren, die in allen Städten Syriens und Egyptens sich neben den katholischen Missionen niederlassen [...]. Auch gegen die Anmassungen und den empfindlichen Druck der übermüthigen, in Religionssachen aber höchst unwissenden Griechen würden die katholischen Missionäre mit solchen religiös und intellectuel bildenden Schriften mit Vortheil auftreten können, wenn sie ihrer Geldkraft eine religiös-erleuchtete Geistesstärke entgegenstellen können [...].

Der Ausführer dieser Idee wurde P. Sebastian Frötschner, nach seiner Rückkehr nach Wien selbst als Generalkommissär tätig.

Die Beobachtungen des Görzer Professors - rezipiert sowohl von kirchlicher wie auch von staatlicher Seite - sind in ihren Auswirkungen den zeitlich früher erfolgten Initiativen Salzbachers gleichzustellen.

Um die finanzielle Situation des Generalkommissariats und seine anfänglichen Kapazitäten zu illustrieren, seien an dieser Stelle einige Zahlen genannt. Aus den Sammlungen der Jahre 1842 und 1843 waren bis zur Übernahme vom k.k. Universalkameralzahlamt im Oktober 184364249 fl. 1 2/4 kr. an Obligationen hervorgegangen ${ }^{70}$. Bis 1852 wurde - neben der Unterstützung konkreter Vorhaben - der Kustodie eine Barsumme von $150000 \mathrm{fl}$. zur Verfügung gestellt ${ }^{7 !}$.

${ }^{69}$ Milde an Metternich, Wien, 1846 May 4, mit der Beilage $\gg D i e$ katholische Mission des heiligen Landes im Jahre 1845 «, in: HHStA, AR, F 53, K 5.

${ }^{70} \mathrm{Vgl}$. Rechnungs-Ausweis des General-Kommissariates der heil. Länder über sämmtliche zur Unterstützung der katholischen Missionen im heiligen Lande im Laufe des I. Verwaltungs-Jahres, d.i. vom 30 . Mai 1844 bis 22 . März 1845 eingegangene Geldbeträge, in: Missions-Notizen aus dem heiligen Lande 1 (1846).

$7 \mathrm{Vgl.} \mathrm{ZSCHOKKE,} \mathrm{Das} \mathrm{österreichische} \mathrm{Pilgerhaus} \mathrm{in} \mathrm{Jerusalem,} \mathrm{S.} 138$. 
Nach Einholung entsprechender Auskünfte wurde am 19. Dezember 1845 im Generalkommissariat beschlossen, die aus Obligationen hervorgegangenen $1789 \mathrm{fl} .47 \mathrm{kr}$. C.M. wie auch eine einstweilige Unterstützung von $10000 \mathrm{fl}$. C.M. nach Jerusalem zu senden; des weiteren alle Gegenstände anzuschaffen, die der Kustos erbeten hatte, darunter eine Druckpresse mit neun Zentnern arabischen und zwölf Zentnern lateinischen Lettern samt allem Buchdruckerund Buchbinderzubehör ${ }^{72}$.

Diese nach Jerusalem übersandten Materialien stellten den Beginn der Buchdruckerei im Franziskanerkloster St. Salvator dar - ein mit österreichischem Geld gestartetes Unternehmen, auf das aufgrund der Anregung von Mosetizh nahezu von Beginn der Tätigkeit des Generalkommissariats an ein Hauptaugenmerk gelegt wurde und dem in den Anfangsjahren österreichischen Engagements in und für das Heilige Land eine zentrale Stellung zukam. »Gründungsvater« Frötschner selbst berichtete:

Mit dem Jahre 1847 beginnt in der palästinischen Mission eine neue Aera. Obwohl in Syrien und Egypten die Druckpressen früher schon mehr oder weniger thätig waren, so mußte doch unsere Mission, wegen Mangel an Mitteln bis auf die neueste Zeit derselben entbehren, und den nöthigen Bücherbedarf für hohes Geld immer aus Europa beziehen. Nun aber ist Guttenberg's Werkstätte für die Katholiken Palästina's selbst in der heil. Stadt Jerusalem aufgeschlagen, ja sie wirkt bereits zum Nutzen und Frommen unserer heil. Religion auf ganz erfreuliche Weise, indem ich auf der von Wien mitgebrachten Hebelpresse schon einige Werkchen an den Tag gefördert habe, die mit unbeschreiblicher Begeisterung von unserem Volke aufgenommen waren. - Daß mir keine leichte Aufgabe ward - hierorts - und ganz allein - eine Druckerei auf- und einzurichten, bedarf wohl keiner Erwähnung; die Hauptaufgabe war aber die rasche Heranbildung der Setzer und Drucker $[\ldots]^{73}$.

Zu letzterem Zweck nahm Frötschner Einheimische, einen Erwachsenen sowie drei Knaben zwischen 13 und 15 Jahren, in die Lehre. Die franziskanische Druckerei stellte für die einheimische Jugend Schul- und Gebetbücher in arabischer und italienischer Sprache her sowie süberhaupt den für Kirche, Schule und Volk nöthigen Bedarf guter und angemessener Bücher zur Förderung wissenschaftlicher und religiöser Zwecke«; ihre Tätigkeit wurde bisweilen sogar von der Propaganda in Rom selbst in Anspruch genommen ${ }^{74}$. Die zu Direktoren bestimmten Franziskaner-Priester - auf den Pionier P. Sebastian Frötschner folgten P. Andreas Hüttisch bzw. P. Heribert Witsch - wurden in der Wiener k.k. Staatsdruckerei ausgebildet.

Die zweite österreichische Unternehmung der Anfangsjahre, die jedoch einer weitaus längeren Vorbereitungszeit bedurfte, resultierte aus der Verbindung des Generalkommissariats mit den Pilgerreisen aus den österreichischen

${ }^{72} \mathrm{Vgl}$. $\mathrm{X}$. Das Wirken des General-Commissariates, in: Missions-Notizen aus dem heiligen Lande 1, S. 32f., 35.

${ }^{73} \S \mathrm{V}$. Die neue Buchdruckerei in Jerusalem, Bericht des P. Sebastian Frötschner ddo. Jerusalem 12. Dez. 1847, in: Missions-Notizen aus dem heiligen Lande 3 (1849) S. 19-23, hier S. 20.

${ }^{74}$ ZSCHOKKE, Das österreichische Pilgerhaus in Jerusalem, S. 138. 
Kronländern: das österreichische Hospiz in Jerusalem ${ }^{75}$, dessen Bau und Verwaltung aus den Sammelgeldern des Generalkommissariats finanziert wurden: "Auf diese Weise hat der Wohlthätigkeitssinn aller Kronländer des österreichischen Kaiserstaates jahrelang zusammengewirkt, um ihren Religions- und Stammesverwandten in der fernen Fremde eine Herberge zu bereiten, wo durch ihre bei dem General-Kommissariate hinterlegten Opfergaben die verdienstvollsten Werke der christlichen Barmherzigkeit geübt werden. $\ll^{76}$

Von Anfang an war großer Wert auf die Absendung von Beichtvätern für die Pilger aus der Monarchie gelegt worden, auch wenn zunächst nur einige wenige - vereinzelte - Europäer die beschwerliche Reise auf sich nahmen. So kamen von Anfang Januar bis Ende Juni 1846 neben fünf Amerikanern insgesamt 286 Europäer ins Franziskanerhospiz (»Casa nova«) in Jerusalem, darunter 266 Katholiken, wovon 34 »rein deutscher Zunge« waren. 18 Personen aus den österreichischen Kronländern Ungarn, Kroatien, Böhmen, Illyrien und Lombardo-Venetien sind an dieser Stelle aufgelistet; damals führend Ungarn mit sieben Pilgern und Lombardo-Venetien mit acht, unter letzteren als Begleitung zweier Adeliger erwähnt eine Ehefrau und drei Bedienstete ${ }^{77}$. Von diesen bescheidenen Anfängen ausgehend, entwickelte sich das Pilgerwesen mehr und mehr in Richtung einer nationalen und konfessionellen Demonstration, in Richtung der großen, von Oberst Heinrich Himmel von Agisburg um die Jahrhundertwende von Tirol aus initiierten, alle Bevölkerungsschichten einschlieBenden "Volkswallfahrten«, die jeweils etwa 500 Menschen aus ÖsterreichUngarn ins Heilige Land führten.

Die Hospiz-Chronik beginnt mit einem Hinweis auf die Rolle von Generalkommissär Matzek bei der Gründung des österreichischen Nationalinstitutes eines Hospizes: „Schon im Jahre 1851 wurde von P. Joseph Matzek, damaligem General-Commissär des hl. Landes, der eigens eine Reise zur Kenntnisnahme der Verhältnisse in Palästina unternommen hatte und fast 10 Monate zu diesem Zwecke verwendete, auf die Nothwendigkeit eines Pilger-Hospitals in Jerusalem hingewiesen. ${ }^{78} \mathrm{Zu}$ einem weiteren unentbehrlichen Motor der

${ }^{75}$ Siehe zum folgenden insbesondere: Helmut WOHNOUT, Das österreichische Hospiz in Jerusalem. Geschichte des Pilgerhauses an der Via Dolorosa, Wien, Köln, Weimar 2000.

${ }^{76}$ Bericht des General-Kommissariates des heiligen Landes über den Bau, die Einrichtung und die Benützung des österreichischen Pilgerhauses zu Jerusalem, in: Wiener Diöcesanblatt, Jg. 1865, S. 86-89, hier S. 87.

${ }^{77} 14$ Männer werden namentlich angeführt. Vgl. § II. Wallfahrten nach Jerusalem, in: Missions-Notizen aus dem heiligen Lande 2 (1847) S. 11-14. Im zweiten Halbjahr 1846 wurden 126 Europäer verzeichnet, darunter acht Männer aus den österreichischen Kronländern: zwei aus »Oesterreich«, drei aus Ungarn sowie je einer aus Böhmen, Mähren und Illyrien, vgl. $\S$ VI. Europäische Besucher am Grabe Christi, in: Missions-Notizen aus dem heiligen Lande 3 (1849) S. 23f.

${ }^{78}$ Chronik I des östr.ung. Pilgerhauses, fol. 1, in: Österreichisches Hospiz, Jerusalem - Archiv. 
Hospiz-Gründung wurde, unterstützt von den Wiener Erzbischöfen und dem Ministerium des Äußern, Konsul Pizzamano.

Die Gründung des österreichischen Pilgerhauses in Jerusalem ist auch zurückzuführen auf den Konflikt, der zwischen der Kustodie und dem 1847 wieder neu eingesetzten Patriarchen von Jerusalem in finanzieller Hinsicht entflammt war: Die Propaganda fide in Rom stellte mit Dekret vom 9. September 1851 die Sammelgelder aus den katholischen Ländern der freien Verwendung des Patriarchen anheim - die vom Kaiser sanktionierten Vorschriften für das Generalkommissariat in Wien ermächtigten den Generalkommissär jedoch nur, den Missionen in Palästina die österreichischen Sammelgelder für bestimmte Zwecke zu senden. Dieser Konflikt wurde so zum Auslöser für die Umsetzung des bereits seit längerem gehegten Plans eines Spitals für die österreichischen Pilger ${ }^{79}$. Wegen Widerstandes von seiten des Patriarchen, der gerade selbst ein großes Spital gebaut hatte, modifizierte Österreich seinen Plan jedoch. Der Grundstein für das an der für die christliche Memoria höchst bedeutsamen Via dolorosa gelegene nunmehrige Hospiz konnte am 31. Dezember 1856 gelegt werden, die Einweihung des Hauses durch Patriarch Valerga erfolgte jedoch erst 1863. Die Leitung des Hauses wurde sozusagen als Kompromißlösung zwei Weltpriestern aus der österreichischen Monarchie übertragen, was in weiterer Konsequenz wiederum zu Konflikten zwischen Säkular- und Regularklerus führte. Mit dem Hospiz besaß der österreichische Kaiserstaat nun in Jerusalem "an jenem ewig denkwürdigen Wege, welchen Christus mit seinem Blute für alle Zeiten geheiligt hatte, ein stattliches Pilgerhaus, eine heimathliche Stätte, auf die ein jeder österreichische Unterthan kraft seines Bürgerrechtes Anspruch hat ${ }^{80}$.

Die Institution des Hospizes - in dem auch Kaiser Franz Joseph während seiner aufsehenerregenden Orientreise im Jahr 1869 Unterkunft nahm - war sicherlich eine der Hauptursachen für den Aufschwung, den das Pilgerwesen aus der Monarchie in der Folge nahm: Nach französischem Vorbild waren vom Vorstand des Wiener Severinusvereins seit 1855 kleinere Pilgerzüge ins Heilige Land organisiert worden, die nach dem Krieg mit Italien wieder aufgenommen wurden. Ende 1864 wurde das Generalkommissariat von seinem Protektor, Fürsterzbischof Rauscher, »im Interesse der Religion, wie auch der administrativen Einheit der Verwaltung der Anstalt beauftragt, die Einleitungen zu den jährlichen Pilgerzügen nach Jerusalem, welche bisher der Severi-

${ }^{79}$ Auch wollte man das französische Protektorat umgehen, und das Franziskanerhospiz in Jerusalem erwies sich der wachsenden Zahl der Pilger nicht mehr gewachsen. Vgl. EISTERER, Erste allgemeine österreichische Pilgerfahrt, S. 145f. Die Sammelgelder waren nach den Statuten zudem nicht nur für die Diözese Jerusalem bestimmt, sondern desgleichen für die Missionen in Ägypten und Syrien; weiters mußte der Unterstützung der nach Palästina reisenden Pilger Rechnung getragen werden. Vgl. ZSCHOKKE, Das österreichische Pilgerhaus in Jerusalem, S. 140.

${ }^{80}$ ZSCHOKKE, Das österreichische Pilgerhaus in Jerusalem, hier S. 132. 
nusverein getroffen hatte, zu übernehmen«. Das Generalkommissariat erwirkte infolgedessen vom Verwaltungsrat der Dampfschiffahrtsgesellschaft des österreichischen Lloyd in Triest eine Fahrpreisermäßigung für die Teilnehmer der Pilgerzüge; die Gelder wurden den Pilgerkarawanen zur Selbstverwaltung übergeben; in den Reiseplan wurden außer Jerusalem und seiner Umgebung noch Ägypten bis Kairo sowie die ganze Landreise durch Samaria und Galiläa bis nach Nazareth, zum Berg Tabor, zum See Genezareth und zum Berg Karmel aufgenommen; sämtliche Teilnehmer der Pilgerzüge fanden Aufnahme im österreichischen Hospiz in Jerusalem ${ }^{81}$. Im ersten Verwaltungsjahr des Hauses wurden 73, im zweiten 155 Pilger verpflegt. »Vergleicht man nun die geringe Ziffer der europäischen Pilger, welche das General-Kommissariat in seinen früheren Berichten aufzuführen vermochte, mit den Verzeichnissen der jüngsten zwei Jahre, so gewahrt man mit Freude, daß der Besuch der heiligen Stätten Palästina's durch europäische Wallfahrer in überraschender Weise zunimmt. ${ }^{82}$ Matthias Eisterer, Pfarrer in Wiener-Neudorf bei Wien, berichtet in seinem Reisebericht über die erste allgemeine österreichische Pilgerfahrt 1898, daß bisher über 4000 Pilger aus Österreich-Ungarn sowie einige hundert "Ausländer« im Hospiz Unterkunft gefunden hätten ${ }^{83}$. Auch die großen Unternehmungen des Oberst Himmel wurden in Kooperation mit dem Generalkommissariat durchgeführt, so reiste Generalkommissär $P$. Angeli zum Beispiel dem Tiroler Papst- und Kaiserjubiläums-Pilgerzug vom Jahr 1898 bis Jaffa voraus, um den Empfang der 507 männlichen Teilnehmer vorzuberei$\operatorname{ten}^{84}$.

Ausblick auf die Jahre 1893-1895:

Trennung des Hospizes vom Generalkommissariat

Die enge Verknüpfung des Generalkommissariats mit dem Hospiz wurde in den neunziger Jahren des 19. Jahrhunderts im Anschluß an die Auseinandersetzungen in den Anfangsjahren und an Jahrzehnte ohne Beanstandungen aufgebrochen $^{85}$. In der Amtszeit Kardinal Gruschas (1890-1911), dem auf Seite des Generalkommissariats P. Angeli entgegenstand, eskalierte die grundlegen-

${ }^{81}$ Ibid. S. 135f., 138f., Zitat S. 138. Die Pilgerbücher der Hospize der Kustodie belegen nach Zschokke, daß der österreichische Kaiserstaat durch seine Pilger unter allen europäischen Großmächten bis zur Wiedererrichtung des Generalkommissariats am schwächsten vertreten war. Ibid. S. 144.

${ }^{82}$ Bericht des General-Kommissariates des heiligen Landes über den Bau, die Einrichtung und die Benützung des österreichischen Pilgerhauses zu Jerusalem, in: Wiener Diöcesanblatt, 1865 , S. 87.

${ }^{83} \mathrm{Vgl}$. EISTERER, Erste allgemeine österreichische Pilgerfahrt, S. 149.

${ }^{84} \mathrm{Vgl}$. STummer, Tirol an des Erlösers Grab, S. 124. Zu den Teilnehmern ibid. S. 32.

${ }^{85} \mathrm{Vgl}$. zum Konflikt um die Verwaltung des Hospizes WOHNOUT, Das österreichische Hospiz in Jerusalem, S. 58-68. 
de Auseinandersetzung zwischen diesen beiden kirchlichen Institutionen ${ }^{86}$; die anstehenden Fragen konnten nur in Rom gelöst werden.

In der im November 1897 in Wien abgehaltenen Bischofskonferenz war das Hospiz wie so oft in den neunziger Jahren wieder einmal Sitzungsgegenstand. Im gedruckten Protokoll findet sich eine knappe, für die Sichtweise der Wiener Erzbischöfe aber sehr aufschlußreiche Darstellung »Zur Geschichte des österreichisch-ungarischen Hospizes in Jerusalem ${ }^{87}$, die den angesprochenen Konflikt folgendermaßen darstellt: Als Rektor Johann Fahrngruber 1879 nach St. Pölten zurückkehrte und sich wegen Priestermangels kein anderer Bewerber fand, wurde der durch die Aufhebung seines franziskanischen Ordenshauses in Venedig »ohne eigentliche Säcularisierung « außerhalb des Ordens stehende (Franz) Joseph Costa-Major von Kardinal Kutschker zum Rektor des Pilgerhauses ernannt und dort auf unbestimmte Zeit belassen. Nach CostaMajors Tod weigerte sich der Generalkommissär, Richard Joch und Franz Kyzlink - dem neuen Rektor und Vizerektor - wie üblich das Reisegeld und den Gehalt auszubezahlen, »indem er sagte, der hl. Vater habe bestimmt, dass [sic!] alles, was beim Commissariat einlaufe, dem P. Custos übergeben werden solle. Er könne also den Weltpriester-Rectoren nichts geben, ohne sein Gewissen zu beschweren. Zum Nachdrucke wies er auch noch ein Telegramm seines P. Generals vor: >Non potes solvere pro itinere Rectoris ‘ « Erst der strikte Befehl des Erzbischofs und die schriftliche Versicherung, daß man die Sache in Rom verhandeln werde, brachten ihn dazu, das Reisegeld herauszugeben. Bald darauf lie $B$ er die beiden Rektoren in Jerusalem aber wieder lange Zeit ohne Mittel, so daß sie gezwungen waren, Schulden zu machen. »Unterdes war auch ein Streit über die Nachlassenschaft Costa Majors entstanden, und musste die Zugehörigkeit desselben zum Orden anerkannt werden.«

Gruscha wandte sich schließlich unter dem 20. März 1893 an den Heiligen Stuhl, um eine Erklärung zu erreichen, daß das Generalkommissariat weiterhin nach seinen besonderen Statuten geleitet und das Hospiz aus den Sammelgeldern des Generalkommissariats erhalten werde ${ }^{88}$. Die Propaganda antwortete unter dem 6. Mai 1893: „Ut pecuniae summa, quae pro Terra Sancta colligitur, detractis impensis, quae in hospitium Austro-Hungaricum aguntur, ad Patrem

${ }^{86}$ Als Rektoren des Hospizes fungierten in jenen Jahren Richard Joch bzw. als sein Nachfolger Franz Maleček aus der Erzdiözese Prag. Vgl. zu ihnen: Reihenfolge der Vorsteher, in: Jahrbuch des österr.-ungar. Pilgerhauses »Zur heiligen Familie« in Jerusalem, hg. vom Kuratorium, Jg. 2, Wien 1908, S. 23-26, hier S. 25.

${ }^{87}$ Zur Geschichte des österreichisch-ungarischen Hospizes in Jerusalem, in: Protokoll der bischöflichen Versammlung in Wien vom 23. bis zum 27. November 1897, S. 121f., hier S. 122, in: DAW, BIKO, Karton 8, 1887-1900.

${ }^{88} \mathrm{Vgl}$. Gruscha an Leo XIII., Viennae, die 20. Martii 1893, in: HHStA, KA Jer., K 130 , fol. $645 \mathrm{r}-647 \mathrm{v}$. 
Custodem per Commissarium integra transmittatur. ${ }^{89}$ Dieses Gruscha hochzufriedenstellende Dekret wurde dem Generalkommissär mitgeteilt; zugleich wurde diesem aufgetragen, einen Vermögensnachweis des Generalkommissariats, ein Verzeichnis der bei demselben bestehenden Stiftungen und die seit Juli 1892 ausständige Jahresrechnung vorzulegen ${ }^{90}$.

Dennoch dauerte die endgültige Klärung der Frage bis 1895, vor allem weil von der Propaganda in Rom widersprüchliche Anordnungen zurückkamen. So übermittelte Kardinal Ledóchowski mit 22. Juni 1894 ein weiteres Reskript, in dem er eine andere Rechtsmeinung vertrat, aber bereits die Trennung des Pilgerhauses vom Generalkommissariat vorschlug.

Kardinal Gruscha erklärte sich im November 1894 damit einverstanden - im Gegenzug sollte das Generalkommissariat aus seiner Abhängigkeit gegenüber dem Wiener Erzbischof herausgelöst werden und den päpstlichen Konstitutionen gemäß nur mehr dem Ordensgeneral und der Propaganda verpflichtet sein -, bat die Propaganda aber um Erhöhung der aus den Sammelgeldern zum Unterhalt des Hospizes bestimmten Summe von $4000 \mathrm{fl}$. auf $6000 \mathrm{fl}$. Mit Reskript der Propaganda vom 31. Januar 1895 wurde das Pilgerhaus vom Generalkommissariat getrennt, die Unterordnung des Hospizes unter die Jurisdiktion des jeweiligen Fürsterzbischofes von Wien bestimmt und weiters angeordnet, daß jährlich $6000 \mathrm{fl}$. aus den Karfreitagskollekten für das Hospiz zu verwenden $\operatorname{seien}^{91}$.

Zum Vorsitzenden des von Kardinal Gruscha hierauf für die Verwaltung des Hospizes neu eingesetzten dreiköpfigen Kuratoriums berief dieser einen der maßgeblichsten Männer des »katholischen Österreich«, die sich um die Beziehungen der Monarchie zum Heiligen Land annahmen: Hermann Zschokke, von 1864 bis 1866 selbst Rektor des österreichischen Hospizes in Jerusalem und Verfasser eines verbreiteten Pilgerführers, der als Professor und Rektor der Wiener Universität auch eine wissenschaftliche Karriere machte, als Hofrat im Ministerium für Unterricht und Kultus für kirchliche Angelegenheiten zuständig war und als Prälat und Mitglied des Wiener Domkapitels direkten Zugang zu Kardinal Gruscha hatte ${ }^{92}$.

${ }^{89}$ „Daß die Summe der Gelder, die für das Heilige Land gesammelt werden, abzüglich der Kosten, die für das österreichisch-ungarische Hospiz aufgewendet werden, dem Pater Kustos durch den Kommissär vollständig übergeben werden soll. « (Übersetzung d. A.).

${ }^{90}$ Zur Geschichte des österreichisch-ungarischen Hospizes in Jerusalem, in: Protokoll der bischöflichen Versammlung in Wien vom 23. bis zum 27. November 1897, S. 121f., hier S. 122, in: DAW, BIKO, Karton 8, 1887-1900.

${ }^{11} \mathrm{Vgl}$. Gruscha an Ledóchowski, Viennae, die 27. Novembris 1894, in: HHStA, KA Jer., K 130, fol. 649r-652r; Ledóchowski an Gruscha, Roma, li 31 januarii 1895, ibid. fol. $653 \mathrm{r}-654 \mathrm{r}$.

${ }^{92}$ Vgl. WOHNOUT, Das österreichische Hospiz in Jerusalem, S. 62; Hermann ZSCHOKKE, Führer durch das heilige Land für Pilger, Wien 1868. 
Unter dem 6. September 1895 wurde Gruscha vom Minister für Kultus und Unterricht, Eduard Rittner, darüber verständigt, daß der Kaiser mit EntschlieBung vom 23. August 1895 die Neuordnung der Verhältnisse des in Wien bestehenden Kommissariats des Heiligen Landes und des österreichischungarischen Pilgerhauses in Jerusalem zur Kenntnis genommen habe: »Hiernach erscheinen die durch die Allerhöchste Entschließung vom 14. November 1843 in Ansehung eines Commissariatus terrae sanctae in Wien Allerhöchst genehmigten Einrichtungen und die unterm 16. December 1843 verlautbarten ,Grundregeln und Vorschriften für das General-Commissariat der heiligen Länder außer Wirksamkeit gesetzt. $\ll^{93}$

Das Kräftemessen um Generalkommissariat und Hospiz hatte endlich ein Ende gefunden. Der Wiener Erzbischof behielt seine starke Position hinsichtlich des österreichischen »Nationalinstituts« in Jerusalem, und das Generalkommissariat erfuhr die einschneidendste Veränderung hinsichtlich seiner Struktur.

\section{Le commissariat général de Terre Sainte à Vienne - une rédecouverte du XIX siècle}

$\mathrm{Au}$ milieu du $\mathrm{XLX}^{\mathrm{e}}$ siècle, la wcatholique Autriche« a à nouveau recours à une institution ecclésiale qui avait été fondée une première fois au moment de la Contre-Réforme (1633): le "Commissariat général de Terre Sainte« de Vienne, abrité dans le couvent franciscain du lieu et qui est à percevoir dans le cadre d'une évolution internationale. Après son rétablissement, en 1843, ses activités ont pour objectif un impact d'envergure au sein de la population de la monarchie des Habsbourg, ce qui illustre le rôle très fort encore valable au $\mathrm{XIX}^{e}$ siècle de la religion dans le cadre de la politique et de la société. Au départ, le domaine d'action du Commissariat général de Vienne porte sur l'ensemble du Saint-Empire romain germanique; il a pour fonction d'être le lieu central de collecte et de gestion des toutes les quêtes destinées à la Terre Sainte et à la Custodie franciscaine. Il est supprimé en 1784, à la suite de dénonciations officielles visant des dysfonctionnements. La période couverte par le présent article s'étend jusqu'en 1895, année de l'extraction de la gestion de l'hospice autrichien de Jérusalem du ressort du Commissariat général.

Le rétablissement du Commissariat général de Vienne est à percevoir sur fond des développements réformateurs dans l'Empire ottoman, des événements politiques mondiaux, des mesures ecclésiastiques et d'un ensemble de courants spirituels et politique marquant l'Europe, parmi lesquels le concept de »croisade pacifique«. En Autriche, ce rétablissement s'inscrit en parallèle à l'autorisation renouvelée d'une quête de la Semaine sainte en faveur des Lieux saints (1842) et à l'ouverture d'un vice-consulat autrichien à Jérusalem (1849). Le chanoine de la cathédrale Saint-Étienne de Vienne, Joseph Salzbacher, est amplement impliqué dans toutes ces initiatives.

Pour éviter la répétition des expériences de la fin du XVIII siècle, le prince-évêque de Vienne, Vinzenz Eduard Milde, élabore des »Règles de conduite et instructions pour le Commissariat général des Terres Saintes« en 21 points, qui comprennent des changements

${ }^{93}$ Rittner an Gruscha, Wien, 1895 September 6, in: DAW, Präsidialia I 6, Österr. Pilgerhaus in Jerusalem, Kassette 2. 
conséquents par rapport à sa structure précédente: dorénavant le Commissariat général est placé sous le protectorat de l'archevêque de Vienne, les quêtes sont organisées par les ordinaires épiscopaux et les sommes recueillies doivent être utilisées exclusivement au profit de buts bien définis - c'est cette condition qui favorise plus tard la création d'une imprimerie à Jérusalem, de même que, projet le plus important faisant l'objet de nombreuses oppositions, l'édification d'un hospice autrichien pour pèlerins dans la Ville Sainte. Le premier Commissaire général du XIX ${ }^{\mathrm{E}}$ siècle, le P. Joseph Matzek, entre en fonction le 30 mai 1844. S'étendent alors ses domaines d'activité: outre le recueil et le transfert des sommes les plus importantes possibles au profit des couvents et hospices de la Custodie, on a le souci d'expédier comme missionnaires de plus en plus de Franciscains autrichiens, eux qui doivent jouer le rôle de guides et de confesseurs des pèlerins issus de la monarchie. L'œuvre missionnaire ne s'effectue toutefois pas seulement vers l'extérieur, elle prend également place par le biais de séances informatives, de publications, de la mise en place de pèlerinages et la création d'associations. Dans tout cela, les Franciscains obtiennent constamment l'appui de la Maison de Habsbourg.

Le résultat de l'épreuve de force qui a lieu autour du Commissariat général et de l'hospice dans les années 1890 aboutit en 1895 à la séparation entre les deux institutions (l'hospice pour pèlerins devenant alors du ressort de l'archevêque de Vienne); ce nouvel ordonnancement aboutit à la fin de la validité des »Règles de conduite et instructions pour le Commissariat général de Terre Sainte《. 
